NBER WORKING PAPER SERIES

\title{
GENTRIFICATION AND THE AMENITY VALUE OF CRIME REDUCTIONS: EVIDENCE FROM RENT DEREGULATION
}

\author{
David H. Autor \\ Christopher J. Palmer \\ Parag A. Pathak \\ Working Paper 23914 \\ http://www.nber.org/papers/w23914 \\ NATIONAL BUREAU OF ECONOMIC RESEARCH \\ 1050 Massachusetts Avenue \\ Cambridge, MA 02138 \\ October 2017
}

\begin{abstract}
We thank seminar participants at NBER Summer Institute (Crime and Real Estate Sessions), Berkeley-Haas, UBC-Sauder, and the Urban Economics Association, as well as our discussants Ingrid Gould Ellen, Kevin Lang, and Jacob Macdonald for helpful comments and suggestions. Anthony Braga and Sara Heller provided terrific comments. We acknowledge generous financial support from the Lincoln Institute of Land Policy (TDA051711), the National Science Foundation (SES-962572), and the Alfred P. Sloan Foundation (B2009-47). Palmer thanks the National Science Foundation Graduate Research Fellowship (grant 0645960) and the Fisher Center for Real Estate and Urban Economics. We are grateful to Sookyo Jeong, Andrew Garin, Sam Hughes, Karen Scott, Yuqi Song, and Daniel Sullivan for their extraordinary research assistance, and to Rich Sevieri and Lt. Daniel Wagner of the Cambridge Police Department for facilitating extensive access to Cambridge Police archives. The views expressed herein are those of the authors and do not necessarily reflect the views of the National Bureau of Economic Research.
\end{abstract}

NBER working papers are circulated for discussion and comment purposes. They have not been peer-reviewed or been subject to the review by the NBER Board of Directors that accompanies official NBER publications.

(C) 2017 by David H. Autor, Christopher J. Palmer, and Parag A. Pathak. All rights reserved. Short sections of text, not to exceed two paragraphs, may be quoted without explicit permission provided that full credit, including $(\odot$ notice, is given to the source. 
Gentrification and the Amenity Value of Crime Reductions: Evidence from Rent Deregulation David H. Autor, Christopher J. Palmer, and Parag A. Pathak

NBER Working Paper No. 23914

October 2017

JEL No. D61,R21,R23,R28

\begin{abstract}
Gentrification involves large-scale neighborhood change whereby new residents and improved amenities increase property values. In this paper, we study whether and how much public safety improvements are capitalized by the housing market after an exogenous shock to the gentrification process. We use variation induced by the sudden end of rent control in Cambridge, Massachusetts in 1995 to examine within-Cambridge variation in reported crime across neighborhoods with different rent-control levels, abstracting from the prevailing city-wide decline in criminal activity. Using detailed location-specific incident-level criminal activity data assembled from Cambridge Police Department archives for the years 1992 through 2005, we find robust evidence that rent decontrol caused overall crime to fall by 16 percent-approximately 1,200 reported crimes annually-with the majority of the effect accruing through reduced property crime. By applying external estimates of criminal victimization's economic costs, we calculate that the crime reduction due to rent deregulation generated approximately $\$ 10$ million (in 2008 dollars) of annual direct benefit to potential victims. Capitalizing this benefit into property values, this crime reduction accounts for 15 percent of the contemporaneous growth in the Cambridge residential property values that is attributable to rent decontrol. Our findings establish that reductions in crime are an important part of gentrification and generate substantial economic value. They also show that standard cost-of-crime estimates are within the bounds imposed by the aggregate price appreciation due to rent decontrol.
\end{abstract}

David H. Autor

Department of Economics, E52-438

MIT

77 Massachusetts Avenue

Cambridge, MA 02139

and NBER

dautor@mit.edu

Christopher J. Palmer

Sloan School of Management, E62-539

MIT

77 Massachusetts Avenue

Cambridge, MA 02139

cjpalmer@mit.edu
Parag A. Pathak

Department of Economics, E52-426

MIT

77 Massachusetts Avenue

Cambridge, MA 02139

and NBER

ppathak@mit.edu 


\section{Introduction}

Neighborhood prosperity and safety typically trend in opposite directions: affluent households enter; criminal activity falls; other amenities improve; low-income residents vacate; additional affluent residents enter; and so on 11 These changes in neighborhood characteristics are ultimately equilibrated by price responses in the housing market. In fact, the premise of the popular hedonic method to valuing non-priced neighborhood amenities rests on the existence of such price effects. In a pioneering contribution, Thaler (1978) estimates that a one-standard deviation increase in property crime reduces property values by 3 percent 2 However, the feedback between neighborhood amenities and prices makes it difficult to isolate the contribution of any particular part of the cycle of neighborhood change on prices, absent a large exogenous shock ${ }^{3}$ In this paper, we use the largely unanticipated elimination of rent control regulations in Cambridge Massachusetts in 1995 to study how rent-control induced gentrification affects criminal activity and is capitalized by the housing market 4

Gentrification, which we define as the inflow of households with higher socioeconomic status to urban neighborhoods, can increase or decrease crime 5 On one hand, crime may increase with the influx of relatively affluent residents, who make targets more lucrative. The "collective socialization" view of neighborhoods (see, e.g., Wilson, 1987; Sampson, Raudenbush and Earls, 1997) suggests that gentrification-induced turnover may reduce social cohesion and also increase crime. By contrast, several other forces would cause gentrification to reduce crime. Wealthier residents are more likely to invest in private security measures, such as alarm systems, which deter crime (Farrell, Tilley, Tseloni and Mailley, 2011). Increases in the local property tax base and wealthier residents' influence on municipal priorities may increase resources devoting to crime-fighting. The "broken windows" theory holds that upgrading properties, which generally accompanies gentrification, may deter criminal activity (Wilson and Kelling, 1982). Furthermore, increasing rents may force local residents who commit crimes to relocate. Finally, if gentrification supports increased local economic opportunity, incumbent criminals move away from criminal activity. Mirroring these ambiguous theoretical

\footnotetext{
${ }^{1}$ See Guerrieri, Hartley and Hurst (2013) for theory and evidence on the self-reinforcing cycle of gentrification and property value appreciation.

${ }^{2}$ In more recent studies, Gibbons (2004) finds a 10 percent decrease in property values for a one standard deviation increase in property crime. Bishop and Murphy (2011) employ a dynamic hedonic model to estimate a $\$ 472$ willingness-to-pay to avoid a $10 \%$ increase in nearby violent crime. Pope and Pope (2012) exploits time series variation across zip codes to estimate the elasticity of property value with respect to crime between -0.15 to -0.35 .

${ }^{3}$ Several papers describe issues with the hedonic method and assumptions needed to consistently estimate the willingness to pay (e.g., Bartik (1987), Epple (1987), Bajari and Benkard (2005)). Recent papers have focused on challenges related to omitted variables bias by exploiting comparisons across fine geographic areas such as Black's (1999) study of school quality, and the Linden and Rockoff (2008) and Pope (2008) studies on the housing market impacts of registered sex offenders. Several papers in environment economics exploit quasi-experimental variation stemming from policies such as the Clean Air Act to construct market-driven estimates of the costs of pollution from the housing market (see, e.g., Chay and Greenstone (2005), Sullivan (2017), and Isen, Rossin-Slater and Walker (2017)). See Hilber (2017) for a survey of capitalization effects.

${ }^{4}$ There is no consensus definition of gentrification (see, e.g., Vigdor (2002)). Guerrieri et al. (2013), for instance, define it as an expansion of the footprint of wealthy residents.

${ }^{5}$ A parallel literature examines the reverse channel; for example, Cullen and Levitt (1999) and Ellen, Horn and Reed (2017) document changes in neighborhood composition resulting from changes in local crime.
} 
predictions, the existing empirical evidence on the relationship between crime and neighborhood change is mixed (McDonald, 1986; Van Wilsem, Wittebrood and De Graaf, 2006; Covington and Taylor, 1989; Taylor and Covington, 1988; Lee, 2010; Papachristos, Smith, Scherer and Fugiero, 2011; Aliprantis and Hartley, 2015).

In this paper, we exploit a unique policy change which generates quasi-experimental variation in gentrification to estimate causal effects on crime and validate measures of the potential victimization costs of crime using housing market price reactions. Like many urban areas in the U.S., Cambridge saw sharply rising house prices and falling crime rates during the 1990s. Prior to 1995, Cambridge had widespread stringent rent regulations that depressed housing values, as shown by Autor, Palmer and Pathak (2014). A referendum eliminated rent control in 1995 and generated cross-sectional differences among neighborhoods with varied exposure to rent decontrol. Using data assembled from the archives of the Cambridge Police Department from 1992-2005, we relate these differences across neighborhoods to the spatial distribution of criminal activity over time. We then relate these effects to widely-used external estimates on the victimization costs of crime by Cohen and Piquero (2009) and examine whether they are reasonable since they should not be greater than the overall amount of price appreciation due to rent decontrol 6

Several distinctive features of Cambridge's rent control regime make it particularly well-suited to the analysis of neighborhood-level effects. The rent-control ordinance only applied to a fixed, nonexpanding set of residential units - specifically, non-owner occupied rental houses, condominiums, or apartments built prior to 1969. While only about one third of residential units were subject to rent controls prior to 1995, this fraction frequently exceeded sixty percent in neighborhoods that had older housing stocks and substantial numbers of renters when rent control was enacted in 1970. This neighborhood-level variation allows us to assess the impact of rent decontrol on criminal activity by comparing pre- and post-decontrol changes in the incidence of crime among neighborhoods with different exposures to rent control. Using unique location-specific data on every verified crime in Cambridge between 1992 and 2005, we track the evolution of criminal activity by drawing tight geographic comparisons across narrow slices of the city, while also accounting for aggregate citylevel trends in criminal activity and detailed neighborhood-specific trends at the level of Census tracts. We find robust evidence that rent decontrol caused overall crime to fall by 16 percentapproximately 1,200 reported crimes annually - with the majority of the effect accruing through reduced property crime and public disturbances.

We then quantify the relative importance of neighborhood change's impact on public safety by asking how our estimates on crime and its external costs compare to changes in Cambridge property values due to rent deregulation. Rent decontrol improved housing values through many channels, including upgrading of properties, turnover of tenants and improvements in public safety. The total market valuation of the reduction in crime due to rent control is bounded above by

\footnotetext{
${ }^{6}$ Cohen and Piquero (2009) is an updated version of the Miller, Cohen and Wiersema (1996) report, and has been widely used in cost-benefit calculations and other economic applications. Some examples include Lochner and Moretti (2004), Kling, Ludwig and Katz (2005), Heckman and Masterov (2007), Linden and Rockoff (2008), Dahl and DellaVigna (2009), Deming (2011), and Carpenter and Dobkin (2011).
} 
the total appreciation of the Cambridge housing stock driven by decontrol. We therefore compare price effects from widely-used estimates on the victimization costs of crime by Cohen and Piquero (2009) to the overall price appreciation to gauge whether these external estimates are plausible 7 Autor et al. (2014) show that additional investment activity could at most explain 12 percent of the appreciation of Cambridge residential properties, leaving the rest explained by the capitalization of other benefits of rent decontrol. We find that the crime reduction due to rent deregulation generated approximately $\$ 10$ million (in 2008) dollars of annual direct benefit to potential victims. Capitalizing this benefit into property values, this crime reduction accounts for 16 percent of the contemporaneous growth in Cambridge residential property values due to rent decontrol. This fact implies that the standard cost-of-crime estimates are within the bounds imposed by price appreciation driven by rent decontrol.

We also contribute to a recent literature measuring the indirect consequences of rent-control policies 8 Sims (2007) and Sims (2011) study other aspects of the end of rent control in Cambridge, and study changes to housing-unit quality and neighborhood demographics, respectively. Fetter (2016) finds that strict rent control ordinances contributed to the post-war rise in homeownership. Diamond, McQuade and Qian (2017) use variation from rent-control eligibility changes in San Francisco to estimate the welfare effects of rent control on tenants and landlords. Complementing this body of work, our paper emphasizes how changes in public safety are an important side-effect of housing-market regulations.

The paper proceeds as follows. Section 2 provides brief background on Cambridge's rent control and its demographic changes in the 1990s. Section 3 details our data sources for neighborhood crime and housing markets as well as our measure of exposure to gentrification. Section 4 introduces our empirical strategy and baseline results, and section 5 corroborates these results with several robustness exercises. Section 6 estimates the economic magnitude of the changes in criminal activity we observe and quantifies their relative importance in explaining the housing-market boom experienced by Cambridge from 1995-2005. Section 7 concludes.

\section{Cambridge Rent Control and Demographic Changes}

Seeking to provide affordable rental housing and encourage further development, the state of Massachusetts permitted local municipalities to enact their own rent control ordinances provided they conformed to state guidelines. Cambridge's rent control law went into effect at the end of 1970 and only applied to structures built before January 1, 1969. The ordinance attempted to fix landlord profits at real 1969 levels. The law's administration involved apartment-specific rent ceilings and made it difficult to remove housing units from the rental market. By 1987, rent-controlled units

\footnotetext{
${ }^{7}$ Cohen and Piquero (2009) is an updated version of the Miller et al. (1996) report, and has been widely used in cost-benefit calculations and other economic applications. Some examples include Lochner and Moretti (2004), Kling et al. (2005), Heckman and Masterov (2007), Linden and Rockoff (2008), Dahl and DellaVigna (2009), Deming (2011), and Carpenter and Dobkin (2011).

${ }^{8}$ In more theoretical work, Andersson and Svensson (2014) develop a price equilibrium concept suited to a rentcontrol regime wherein units must be rationed.
} 
were priced about $40 \%$ below market rates 9

By the early 1990s, only Cambridge, Boston, and Brookline had surviving rent-control ordinances. Rent control was relatively popular in those places, and hence local referenda to curtail or eliminate rent control consistently failed. Rent control opponents overcame this impasse by fielding a state-wide ballot initiative that succeeded in putting a rent control question on the November 1994 ballot. The referendum eliminating rent control passed $51 \%$ to $49 \%$, with almost $60 \%$ of Cambridge voters opposed. Rent deregulation in Cambridge began shortly thereafter on January 1, 1995, with a limited number of tenants receiving a 1 to 2 year grace period of protection before complete deregulation.

The top panel of Figure 1 plots the geographic distribution of exposure to rent control by 1990 Census block. In the figure, exposure to rent control, or rent control intensity (RCI), is the fraction of units in the block that were rent controlled. Darker-shaded blocks indicate higher RCI quintiles. While $38 \%$ of residential housing was actively rent controlled in 1994, there is significant spatial variation in RCI across blocks. Denser areas with more rental housing and pre-1969 housing stock often have rent control-market shares exceeding $60 \%$ and are frequently located near blocks with relatively less rent-control exposure. This cross-sectional variation allows us to relate pre- and postderegulation spatial trends in criminal activity to the local gentrification that was induced by the sudden end of rent control in January 1995.

As discussed in Autor et al. (2014), in the years following deregulation, resident turnover increased markedly, rents at newly-deregulated units jumped 40-80\%, landlord investment in deregulated rental units intensified, and property values rose for both deregulated units and never-regulated owner-occupied properties situated in neighborhoods with significant pre-1994 rent-control shares. Table 1 details the demographic changes in Cambridge between the 1990 and 2000 Decennial Censuses, measured at the census tract level 10 Overall, the population of Cambridge became denser, more multiracial, higher income, and more educated. The average tract's share of white-collar workers increased by 23 percentage points. To investigate whether some of these demographic changes were accelerated by the end of rent control, we estimate difference-in-difference regressions that control for tract and time effects. Let $y_{g t}$ be a demographic characteristic in census tract geography $g$ in year $t \in\{1990,2000\}$. Our estimating equation is

$$
y_{g t}=\alpha_{g}+\delta_{t}+\gamma \mathrm{RCI}_{g} \times \mathrm{Post}_{t}+\varepsilon_{g t},
$$

where $\alpha_{g}$ are Census tract fixed effects, $\delta_{t}$ are time effects, $\mathrm{RCI}_{g}$ is Rent Control Intensity measured as the fraction units in the tract subject to rent control, and Post $t_{t}$ is an indicator for 2000. The estimates of $\gamma$ shown in column 4 of Table 1 show that, for the most part, demographic trends were similar in neighborhoods with high and low exposure to rent control. Notably, neighborhoods with high levels of rent control experienced statistically significant relative decreases in the share

\footnotetext{
${ }^{9}$ Additional details of Cambridge's rent control regime and the process of decontrol are provided in Autor et al. (2014). See also Sims (2007), who found that upkeep in regulated units was worse than in unregulated units.

${ }^{10}$ To make tract boundaries comparable, we use geographically harmonized census data provided by Geolytics.
} 
of juveniles living therein and significant increases in the share of residents currently attending college ${ }^{11}$

\section{Data and Measurement}

We briefly discuss our data sources and measurements of rent control intensity in this section, with further details in the Data Appendix.

\subsection{Cambridge Crime Data}

Our microdata on reported crime comes from the Cambridge Police Department archives. The data begin in 1992 and comprise all incidents recorded in real time by the police department as "Calls for Service." Each record contains information on the reported crime, including its date and location. From 1992-1996, the data were recorded on shift logs by typewriter. In 1997, the department switched to an electronic database. To form our sample, we manually enter each incident's relevant details from the physical typewritten pages for 1992-1996 and then append the electronic data for 1997-2005. Occasionally, the location of an incident is specified without an address, e.g., a local business name is provided as the address. In such cases, we manually look up each location and record its nearest street address using tools like Google Maps. We then determine the latitude and longitude of each address so that we can allocate it to various geographies. The crime count in our data set closely tracks the city-wide counts that the Cambridge Police Department provides to the FBI, as discussed further in the Data Appendix.

The bottom panel of Figure 1 plots the geographic distribution of criminal activity by 1990 Census block, averaged across reporting years 1992-2005. Darker-shaded blocks indicate higher quintiles of criminal activity. To measure criminal activity, we average the annual number of total crimes reported in a given block, normalized by block area (1,000 square meters). Criminal activity is most concentrated along commercial thoroughfares and around town squares that also serve as public transit hubs. In comparing the top and bottom panels of Figure 1, criminal activity appears to move more smoothly in space than does exposure to rent control. Nevertheless, there is still substantial within-neighborhood variation in criminal activity.

To measure the effect of rent decontrol on crime, it seems reasonable that changes in crime should be proportional to changes in the level of reported crime. For instance, neighborhoods with little crime may not experience the same reduction in their crime levels as neighborhoods with high levels of crime. A natural specification would therefore examine log of crime as the dependent variable. However, the high frequency of zero reported crimes at the block $\times$ year level prevents such a specification. Instead, we normalize our count of crimes by area, following strategies used in criminology research, and use the number of crimes per 1,000 square meters (see Bowes and

\footnotetext{
${ }^{11}$ Using data at a finer geographic level and more sophisticated racial composition measures, Sims (2011) found evidence that post-rent control turnover decreased minority shares, although segregation decreased slightly as well.
} 
Ihlanfeldt, 2001; Ihlanfeldt and Mayock, 2010; City of New York Police Department, 2015). We also investigate count specifications using Poisson regressions.

We classify each crime incident into crime categories based on the Cambridge Police Department classification system, which closely resembles the FBI Uniform Crime Reporting categories. The four categories and their most frequent components are:

1. Property Crime: Larceny, Burglary, Fraud, Shoplifting, Arson;

2. Public Disturbances: Public Disturbance, Simple Assault, Destruction of Property, Property Damage, Vandalism, Trespassing, Prostitution, Illegal Firearm Possession;

3. Drugs and Alcohol: Possession of Hypodermic Needle, Possession of Class A/B/C/D/E Drugs, Trafficking, Alcohol in Minor's Possession, Unlawful Sale of Alcohol, Possession of Heroin or Marijuana;

4. Violent Crime: Abduction, Murder and Attempted Murder, Rape, Robbery, Aggravated Assault.

Panel A of Table 2 reports summary statistics by crime category at the block level, describing the annual number of crimes per 1,000 square meters by Census block. The table shows that property crime and public disturbance crimes are the most common types of crime in Cambridge, while violent crime and reported drug/alcohol crime are relatively infrequent. There are blocks with zero reported crimes in a given year; there are also blocks with reported crime counts over fifty times the average block's crimes per area, such that the spatial distribution skews right.

Figure 2 plots proportional trends in reported crime by category by plotting log crime counts by category, each normalized to be 0 in 1992. The blue-circles line shows total crime declining significantly and steadily from 1994-1997. By 2000, while each category declined city-wide from 1992 levels by $20 \%$ or more, violent crime and public disturbances fell the most, declining $40-50 \log$ points from $1992-200012$

Since the 1990s are widely seen as a period of improving public safety in urban neighborhoods, it's possible that the decrease in crime in Cambridge is not unusual relative to other cities and therefore has little to do with rent deregulation. To investigate whether Cambridge's experience is distinct and plausibly related to the 1995 policy change, we use data from the FBI Uniform Crime Reports on annual total crimes from 1985-2012 for the 147 cities with populations between 75,000 and 150,000. We chose these comparison cities because Cambridge's population was about 94,000 in 1994. To test whether Cambridge's city-wide experience seems atypical of the urban renaissance experienced by many medium-sized cities during this time period, we estimate the following difference-in-difference specification at the city $c \times$ year $t$ level:

$$
\log \left(\text { total } \text { crimes }_{c t}\right)=\alpha_{c}+\gamma_{t}+\beta \text { Treated }_{c} \times \text { Post }_{t}+\varepsilon_{c t},
$$

\footnotetext{
${ }^{12}$ Appendix Figure A1 presents a version of Figure 2 in levels to compare trends in the relative frequencies of each crime category.
} 
treating each city as the treated city and the rest as controls. That is, we fit equation (1) a total of 147 times, looping over all cities and counting each city as treated (e.g., Treated $_{c}=1$ ) one at a time to characterize where in the distribution of comparison cities Cambridge's crime pattern lies. We define Post to be a dummy for whether year $t$ is greater than or equal to 1995, and $\alpha_{c}$ and $\gamma_{t}$ are city and year fixed effects, respectively. Figure 3 plots the kernel density of these 147 estimated $\hat{\beta}$ coefficients. The modal city's estimate of $\beta$ is negative, and roughly $60 \%$ of city-level coefficients were negative, a result that is consistent with the view that most cities enjoyed declining crime rates throughout the 1990s, as compared to pre-1995, although several medium-sized cities in the data had an increase in total crimes reported post-1995 relative to pre-1995. Cambridge is at the 8.8th percentile of the coefficient distribution, corresponding to a rank of 13 out of 147 . This result - that Cambridge's decrease in crime significantly exceeded the average similarly sized city's drop in crime - also speaks to whether the relative decreases in crime we document below merely represent within-Cambridge displacement of criminal activity from treated neighborhoods to untreated neighborhoods. The fact that crime decreased city-wide in Cambridge after 1994 relative to similarly sized cities across the country over the same time period suggests that our estimated public safety improvements had non-negligible aggregate effects.

\subsection{Defining Neighborhoods and Exposure to Gentrification}

Since our research design exploits cross-neighborhood comparisons of rent control exposure induced by the elimination of rent control, it is necessary to define neighborhoods as well as rent-control exposure. Neighborhoods are commonly defined in terms of Census geographies. However, one drawback of using Census boundaries is that census blocks often align with street center lines, meaning that houses on opposite sides of a street are assigned to different blocks. As a result, blocks do not closely correspond to the geographies perceived by neighborhood residents.

Following best practices in criminology (e.g., Weisburd, Groff and Yang, 2012), we manually adjust Census block boundaries to ensure that both sides of the street are in the same block. We refer to these as adjusted blocks; they can be seen as block faces, i.e. street segments bounded by the two closest cross-streets, as in Ellen, Lacoe and Sharygin (2013), merged to mimic the size of Census blocks. Figure 4 provides an example of this procedure by outlining two blocks in Harvard Square. The left-hand panel shows that the block boundaries in the red and blue rectangles run down the middle of Church Street and JFK Street, meaning that opposite sides of the same street are in different official Census blocks. The adjusted blocks in the right-hand panel, by contrast, have been moved north of Church Street and West of JFK Street so that both sides of the same street are in the same adjusted block. We utilize this adjusted-block concept throughout our analysis.

To measure exposure to gentrification induced by the end of rent control in Cambridge, we calculate the fraction of nearby units (weighted by distance) that were rent controlled prior to January 1995. Autor et al. (2014) show that resident turnover rates, appreciation in rents and property values, and improvements in the quality of the housing stock that accompanied the end of rent control were proportional to the rent-control density of the area. We measure this exposure 
using an exponential decay function to determine the Rent Control Intensity of each adjusted block in Cambridge $g$ as a function of its distance from all other RC (rent controlled) units $j$ in Cambridge, where the weight given to each unit $j$ is declining in its distance from $g$. Let $d_{g j}$ be the shortest distance between the boundary of adjusted block $g$ and the location of housing unit $j$ measured in miles (with $d_{g j}=0$ if housing unit $j$ falls inside of block $g$ ), $\lambda>0$ be a positive constant, $J$ be the complete set of residential units in Cambridge, and $\mathrm{RC}_{j}$ be a dummy variable equal to 1 if unit $j$ is rent controlled and 0 otherwise. For adjusted block $g$, our distance-based measure of gentrification $\mathrm{RCI}^{\lambda}$ is

$$
\mathrm{RCI}_{g}^{\lambda}=\frac{\sum_{j \in J} \mathrm{RC}_{j} \times e^{-\lambda d_{g j}}}{\sum_{j \in J} e^{-\lambda d_{g j}}} .
$$

Higher values of $\lambda$ put less weight on units far away from the current block. As $\lambda$ grows large, this measure puts all of the weight on own-block gentrification. Following Autor et al. (2014), we present results using $\lambda=12$ and examine robustness to alternative specifications using higher and lower values of $\lambda$, including specifications we refer to as $\lambda=\infty$ that only measure RCI at the block level. Panel B of Table 2 reports summary statistics for $\mathrm{RCI}^{\lambda}$ for a range of parameter values for $\lambda$. Average RCI is falling in $\lambda$ while the standard deviation of each RCI measure is increasing in $\lambda$ as larger weights put more emphasis on smaller (and thus more volatile) areas in the exponential decay functional form in 2 .

\section{Empirical Strategy}

\subsection{Research Design}

Disentangling the simultaneous relationship between public safety improvements and gentrification poses a significant empirical challenge due to their co-determination. The unique natural experiment afforded by the sudden end of rent control mitigates many of these issues by providing a clean exogenous measure of exposure to subsequent gentrification forces. Panel data on criminal activity at fine geographies allows us to account for fixed differences across space - most importantly, the heterogeneity that exists in baseline crime levels across neighborhoods within Cambridge - and ascertain whether and how the frequency of reported crimes changed in response to post-rent control gentrification.

Our empirical specifications explain changes in the level of crimes per 1,000 square meters after the end of rent control, as discussed in Section 3.1. Denoting annual crimes per area measure as $y_{g t}$, our baseline specification is

$$
y_{g t}=\alpha_{g}+\delta_{t}+\beta_{0} \mathrm{RCI}_{g}^{\lambda}+\beta_{1} \mathrm{RCI}_{g}^{\lambda} \times \operatorname{Post}_{t}+\varepsilon_{g t}
$$

where $\alpha_{g}$ and $\delta_{t}$ are adjusted Census block and year fixed effects, respectively; $\mathrm{RCI}_{g}^{\lambda}$ is the Rent Control Intensity (exposure measure) of block $g$ given exponential-decay parameter $\lambda$ as specified in equation (2) above, and Post $_{t}$ is an indicator for years 1995 through the end of the sample (2005). 
We cluster our standard errors at the level of the adjusted block, since reported criminal activity in a block is not independent across years 13

The coefficient of interest in this specification is $\beta_{1}$, which measures the differential change in crime in high versus low RCI areas after rent control's elimination. For estimates of $\beta_{1}$ to represent the causal effect of rent decontrol (and the resulting gentrification) on local crime, we require the following identifying assumptions. First, the change in rent control status needs to be exogenous. This seems plausible given the uncertain and close nature of the rent control ballot referendum coupled with strong local opposition to ending rent control. This assumption is also consistent with our event studies, which show that criminal activity in high RCI areas did not seem to be on a differential trend prior to 1995. Second, conditional on the exposure variable RCI, and conditional on our detailed geographic and time fixed effects, RCI $\times$ Post needs to measure only the change in criminal activity caused by the end of rent control and not other factors correlated with rent control intensity but not caused by the end of rent control.

The end of rent control in 1995 coincided with a nationwide period of urban renaissance, which raises the possibility of confounding trends. The time effects $\delta_{t}$ in our estimating model will absorb these changes to the degree that they affect the overall level of reported crimes in Cambridge. Time effects do not absorb any differential safety improvement in rent control-intensive neighborhoods. We address this concern by estimating specifications containing tract trends, in addition to 816 geographic main effects for Cambridge blocks, thereby allowing the rate of falling crime to differ across Census tracts. Section 5 discusses and addresses remaining potential concerns with identification in the context of equation (3).

\subsection{Main Results}

Table 3 presents results from estimating equation (3) for rent decontrol's causal effect on annual reported total crimes per 1,000 square meters at the Census block level from 1992-2005. Each column reports results using a different value of $\lambda$ to calculate Rent Control Intensity, as in equation (2), and the top and bottom panels reflect specifications without and with linear tract trends, respectively. The negative coefficients on $\mathrm{RCI} \times$ Post mean that, relative to a given block's fixed effects, a block with higher exposure to post-rent control gentrification saw a larger annual decrease in crime. To put each coefficient into more readily interpretable units, the table converts each point estimate into a measure of the annual effect on reported crimes of a one standard deviation higher value of Rent Control Intensity (recall from Table 2 that the standard deviation of RCI increases in $\lambda$ ). Focusing on our preferred value of $\lambda=12$ in column 2 of panel A, a block with a one standard deviation higher exposure to rent deregulation can be expected to have a $11.3 \%$ decrease in total crime. Different values of $\lambda$ affect the point estimates somewhat, but with no discernible impact on

\footnotetext{
${ }^{13}$ Appendix Table A1 reports spatial standard errors for our main estimates following Conley (1999). For each estimate in the table, spatial standard errors are smaller than clustered standard errors. Accordingly, we report clustered standard errors in the main tables to be conservative.
} 
$R^{2}{ }^{14}$ Estimates of the effect of a one standard deviation increase in rent control exposure on crime range from a low of $-11.3 \%$ to a high of $-15.4 \%$, showing our preference for $\lambda=12$ to be the most conservative.

We control for differential neighborhood crime pre-trends that could invalidate the estimates in panel A in two ways. First, panel B reports results based on specifications that allow each tract to have its own linear time trend. If public safety on blocks in high-RCI areas is improving faster even before the end of rent control, then the decrease in criminal activity after the end of rent control in those locations could be unrelated to the end-of-rent-control-induced gentrification and instead simply a continuation of secular improvements in certain neighborhoods. Allowing for tract-specific linear time trends allows us to learn whether the decrease in criminal activity we saw in panel A is consistent with not only a decrease in crime relative to baseline crime levels (block fixed effects) but also relative to prevailing trends. The estimated RCI $\times$ Post coefficients in columns 1-5 of panel B are each smaller than their panel A counterparts, but still statistically significant. Instead of a one standard deviation higher exposure to rent control corresponding to a 11-15\% decrease in crime in panel $\mathrm{A}$, the results in panel $\mathrm{B}$ suggest that after accounting for tract trends, a one standard deviation higher RCI measure corresponds to a $7-12 \%$ decrease in criminal activity after the end of rent control.

The second way we test whether our results are driven by differential neighborhood trends is to estimate an event study version of equation (3), replacing RCI $\times$ Post with a full set of interactions between RCI and calendar year dummies. Because of the fixed effects $\alpha_{g}$, we omit $\mathrm{RCI}_{g} \times 1(t=1994)$. This normalization means that the event study coefficients plotted in Figure 5 reflect how criminal activity changed in Cambridge along the dimension of exposure to rent control relative to the relationship between RCI and crime in 1994. Panel A extends the specification of Table 3 panel $\mathrm{A}$ without tract trends, and panel $\mathrm{B}$ adds the tract trends described above in the context of Table 3's panel B. In both panels, there is no statistically detectable trend in criminal activity along the treatment dimension. In fact, while we would be most concerned with a pre-trend that showed crime already falling in high-RCI areas, the plots show that, if anything, crime rose slightly in the years immediately preceding rent deregulation, i.e., 1992-1994, in higher-RCI blocks relative to lower-RCI blocks, although this trend is not statistically significant. It is reassuring that tracts with higher exposure to gentrification caused by the end of rent control do not seem to have been on differential paths before the end of rent control.

The time path of the coefficients in Figure 5 suggest a swift change in criminal activity following the end of rent control, with crime falling significantly from 1994 baseline levels in high vs. low RCI blocks. While the 1995 coefficient is statistically indistinguishable from zero, the 1996-1999 coefficients are consistent with an appreciable drop in total crimes in the years following rent control, a time when resident turnover and residential investment were particularly high in formerly rent-

\footnotetext{
${ }^{14}$ To visualize the relative invariance of $R^{2}$ to choice of weighting parameter $\lambda$, Appendix Figure A2 plots the sum of squared errors from estimating equation (3) for a fine grid of values of the parameter $\lambda$ for specifications with and without tract trends. The SSE envelope is relatively flat, meaning that a wide range of weighting parameters $\lambda$ fit the data nearly equally well.
} 
controlled housing units (Autor et al., 2014). The estimates plotted in both panels are consistent with criminal activity undergoing a permanent relative decrease attributable to gentrification. The estimates with trends in panel B show a slight but incomplete and imprecise convergence back to 1994 crime levels. Taken together, the specifications that allow for tract trends, including the event study plots, provide strong evidence for a causal relationship between the gentrification that followed rent deregulation in Cambridge and decreased in criminal activity from 1995-2005.

We learn from Table 3 and Figure 5 that, after the end of rent control, total crime fell further in the Cambridge neighborhoods that were most exposed to rent control. Which categories of crime were most affected by deregulation-induced gentrification? Table 4 addresses this question by repeating our main specification in column 2 of Table 3 , where the outcome corresponds to particular crime categories. The results suggest that all crime categories experienced statistically significant and economically meaningful declines in crime because of the end of rent control, with the largest effects for public disturbances and drug and alcohol crime. A block with a one standard deviation higher exposure to rent control experiences an $13 \%$ and $14 \%$ decrease in public disturbances and drug- and alcohol-related crime, respectively. Violent crime, which is widely considered far costlier than other categories of crime, also experienced a significant $12 \%$ drop that is attributable to the end of rent control. Comparing these by-category point estimates with the total crimes estimates in Table 3, the estimated effect on total crimes is closest in magnitude to the property-crimes coefficient, driven by that category accounting for the largest share of total crimes (see Table 2). In this sense, focusing on results on total crimes that pool categories together is conservative. Panel B of Table 4 mirrors panel B of Table 3 by controlling for tract trends. As before, this reduces the magnitude of the coefficients with the one standard deviation RCI effects ranging from 5-10\% reductions in crime. Still, all of the point estimates are still negative in the trends specification of panel B, and only the drug and alcohol crime coefficient is statistically insignificant. After exploring alternative estimation approaches (summarized below), we combine external estimates of crime's cost with our point estimates to quantify the these changes' value to public safety, given disparate costs to victims of these different types of crime.

\section{Robustness to Alternative Specifications}

One concern about our empirical approach relates to our choice to specify the dependent variable as (normalized) counts. If secular reductions in crime happen proportionally, that is, the city-wide trend reduces crime by a given percent instead of a given number of crimes, then specifying the dependent variable in levels could indicate a spurious relationship between Rent Control Intensity and reductions in crime. Specifically, if high-RCI areas also have high baseline crime levels and crimes per area fall further in high-crime areas, then estimates of the RCI $\times$ Post coefficient could be biased due to the correlation with initial crime levels.

As discussed above, we would ideally use the logarithm of crimes for our dependent variable, but we are prohibited from doing so by the high frequency of zeroes in the data, especially at the block 
by crime category by year level. Instead, we present several strategies to address this concern - in addition to the trends specifications and event studies reported above-including Poisson regression, nonlinear specifications of RCI that allow the effect to differ across the RCI distribution, and directly controlling for initial crime levels. We also examine whether gentrification that is less clearly related to the end of rent control (e.g., relative improvements in neighborhoods with close proximity to a subway stop) seems to be a stronger predictor than RCI of decreased criminal activity.

\subsection{Alternative Measures of Rent Control Intensity}

Panel A of Table 5 allows for non-linearities in the causal effect of RCI by replacing the RCI $\times$ Post term in equation (3) with interactions between Post and indicator variables for whether block $g$ fell into the second and third RCI terciles. Even-numbered columns report estimates that control for linear tract trends, and odd columns report estimates that do not. Regardless of the $\lambda$ parameter or the trends specification used, the difference between total crime reductions within blocks at the first (omitted category) and second RCI terciles is small and mostly statistically insignificant as well. The strong RCI $\times$ Post results above are thus driven by blocks in highest third level of exposure to post-deregulation gentrification, as seen in the third RCI tercile $\times$ Post results. As before, trends somewhat attenuate the estimated magnitudes, but even allowing for trends and regardless of $\lambda$, blocks in the third RCI tercile had larger declines in criminal activity than blocks with RCI values outside the top third. This is consistent with two possible dynamics: either RCI and crime have a non-linear relationship, with the RCI-crime gradient steepening in RCI; or alternatively, high-RCI areas - which are also more likely to also be high-crime areas - experienced large declines in crime in the 1990s independent of the causal effect of rent deregulation. This latter possibility motivates specifications that directly incorporate initial crime levels, which we discuss below.

We also use fixed-effects Poisson regression, since it is natural for count-data settings (Hausman, Hall and Griliches, 1984). We model the count of total crimes $N_{g t}$ in block $g$ and year $t$ as

$$
N_{g t} \sim \operatorname{Poisson}\left(\bar{N}_{g t}\right)
$$

where the conditional mean of the count of total reported crimes in block $g$ in year $t$ is given by $\bar{N}_{g t}$ and specified as

$$
\log \bar{N}_{g t}=\alpha_{g}+\delta_{t}+\beta_{0} \mathrm{RCI}_{g}^{\lambda}+\beta_{1} \mathrm{RCI}_{g}^{\lambda} \times \text { Post }_{t}
$$

The Poisson specification allows for the effects of gentrification to be proportional to the initial crime level. The coefficient $\beta_{1}$, for example, tells how the log conditional expectation of crime count changes in response to a one unit increase in the given Rent Control Intensity measure. This calculation is particularly useful if the true effect of post-decontrol gentrification is in percentage points, not normalized crime counts. The Poisson specification accounts for this, whereas a specification in levels could potentially have initial crime as an important omitted variable.

The estimates of $\beta_{1}$ in panel $\mathrm{B}$ of Table 5 are all negative but admittedly less precise than our linear-estimator results in Table 3 . The -0.285 coefficient in column 3 means that for a one standard 
deviation increase in exposure to rent control, crime fell by $6 \%$ in the post period. In the fixedeffects Poisson model, including linear tract trends reduces estimated magnitudes by enough that the point estimates in the even-numbered columns are statistically insignificant. The fixed-effects Poisson regression accounts for the possible misspecification of trends by allowing the effect to be additive in logs instead of in levels. However, the sensitivity to trends shown in Table 6 motivates further investigation into the influence of initial crime levels.

\subsection{Robustness to Initial Crime Levels}

To measure the importance of initial crime levels in our normalized crime counts specifications, we next report specifications that control for Initial Crime directly:

$y_{g t}=\alpha_{g}+\delta_{t}+\beta_{0}$ Initial Crime $_{g} \times$ Post $_{t}+\beta_{1} \mathrm{RCI}_{g}^{\lambda} \times$ Post $_{t}+\beta_{2}$ Initial Crime $_{g} \mathrm{RCI}_{g}^{\lambda} \times$ Post $_{t}+\varepsilon_{g t}$,

where $y_{g t}$ is the number of crimes per block group normalized by the geographic area of the block group. The key addition relative to prior linear specifications is the variable Initial Crime ${ }_{g}$, defined as the number of crimes per 1,000 square meters in block $g$ in 1992. Because 1992 crime rates are used to calculate the regressors, 1992 is dropped from the estimation sample. We demean both initial crime and RCI to be able to interpret the main effects directly as the effect of the indicated variable given an average level of the other regressor of interest. We introduce a more flexible function form of this interaction below.

Table 6 first contrasts the bivariate effects of RCI $\times$ Post and Initial Crime $\times$ Post (conditional on block and year fixed effects) in columns 1 and 2 using RCI defined with $\lambda=12$ Both RCI and Initial Crime levels predict differential declines in criminal activity after the end of rent control and explain a similar share of the spatial-temporal variation in crime counts. Column 3 shows that when the correlation between the two is taken into account, as in equation (4), initial crime seems to be a more accurate predictor of subsequent improvements in public safety. Accounting for the fact that these factors may interact in contributing to declining crime, column 4 includes the interaction term Initial Crime $\times$ RCI $\times$ Post. This inclusion reveals that, while initial crime and RCI are both statistically and economically significant negative predictors of lower crime after rent deregulation, their interaction is especially important in explaining falling crime rates.

Table 7 repeats the specification of column 4 of Table 6 for each of our four crime categories. In each column, the interaction term Initial Crime $\times \mathrm{RCI} \times$ Post is strongly negative and significant, while the main effect of RCI $\times$ Post is weaker than in Table 6 , although still negative. The effect of a standard deviation change in RCI on reported crimes in each category, conditional on initial crime, is of the same order of magnitude as the results of Table 4 that do not condition on initial crime, with the exception of Drug and Alcohol crime, which appears to have a more significant reduction related to rent control when accounting for preexisting crime trends.

\footnotetext{
${ }^{15}$ Note that column 1 of Table 6 differs from the estimate in column 3 of Table 3's panel A only in that we have to drop data from 1992 in the Table 6 specifications.
} 
This evidence suggests the effects of rent decontrol-induced gentrification were strongest in neighborhoods that had higher initial crime levels.

\subsection{Flexible Specifications of Initial Crime}

The specifications in panel A of Table 5 suggest that the relationship between RCI, initial crime levels, and subsequent declines in criminal activity may be nonlinear. We probe this further by estimating the relationship nonparametrically with a flexible third-order polynomial function of interactions between RCI and initial crime by estimating

$$
y_{g t}=\alpha_{g}+\delta_{t}+\sum_{k=0}^{3} \sum_{\ell=0}^{3} \beta_{k \ell}\left(\mathrm{RCI}_{g}\right)^{k}\left(\text { Initial Crime }_{g}\right)^{\ell} \times \text { Post }_{t}+\varepsilon_{g t} \text {, }
$$

where the coefficients $\beta_{k \ell}$ estimate the functional relationship between RCI and initial crime in the post period, after controlling for time-invariant heterogeneity across neighborhoods $\alpha_{g}$ and Cambridge-wide time shocks $\delta_{t}$. After estimating this equation, we examine the relationship visually

by plotting the predicted post-period change in crime $\widehat{\Delta y}_{g t}$ against initial rent-control exposure and crime levels in Figure 6, where we define the predicted post-period change in crime as

$$
\widehat{\Delta y}_{g t}=\sum_{k=0}^{3} \sum_{\ell=0}^{3} \hat{\beta}_{k \ell}\left(\mathrm{RCI}_{g}\right)^{k}(\text { Initial Crime } g)^{\ell} \text {. }
$$

Post-rent-deregulation crime in Cambridge strongly declines from initial crime levels, but only for areas with high exposure to gentrification due to previously heavy rent control. This pattern can be seen by considering the initial crime axis of Figure 6. The relationship between initial crime and future changes in crime is flat for all but the highest levels of RCI. The RCI axis also shows that higher rent-control exposure values correlate with deeper declines in reported crime, but this relationship is only detectable for initial crime levels above 3. Figure 6 shows that taken alone, neither high RCI nor high initial crime was sufficient to produce meaningful declines in criminal activity: gentrification improved safety predominantly in the areas with the highest initial crime rates.

\subsection{Other Neighborhood Trends}

Our second identifying assumption is that the $\mathrm{RCI} \times$ Post variable is conditionally unrelated to other dimensions along which gentrification may have been occurring. It's possible that gentrification is in part spurred by improved public safety, which would complicate the interpretation of our result linking gentrification to declines in local crime. Put simply, neighborhoods with high exposure to rent control may also be gentrifying for reasons unrelated to rent decontrol.

To address this concern, we examine several candidate neighborhood characteristics that plausibly correlate with Rent Control Intensity in order to see a) whether these characteristics play a stronger role than Rent Control Intensity in predicting declines in crime and b) whether control- 
ling for these characteristics attenuates the end of rent control's estimate effect on criminal activity. Specifically, we consider a block's proximity (defined as negative distance in kilometers) to the nearest subway station, proximity to the nearest public housing project, and its census tract's initial poverty rate (measured by the 1990 Decennial Census) as three factors that may each simultaneously correlate with secular gentrification trends, decreased local criminal activity, and Rent Control Intensity.

Table 8 reports results on each of these factors as omitted variables in accounting for the effects of rent control exposure. Column 1 repeats the specification of column 1 of Table 6 for reference, showing the statistical significance of RCI $\times$ Post as a predictor of lower reported crimes per area. Columns 2, 6, and 10 show difference-in-difference estimates where the treatment variable is each of the three candidate omitted variables. Columns 3,7 , and 11 test whether the estimated RCI $\times$ Post effect is robust to controlling for each of these factors interacted with Post. Columns 4, 8, and 12 check for meaningful interactions between $\mathrm{RCI} \times$ Post and each omitted variable to see if a similar relationship exists between these factors and rent-control intensity as was demonstrated above in the case of initial crime levels. Finally, columns 5, 9, and 13 additionally include initial crime interacted with Post and each neighborhood factor to examine whether the initial crime relationship itself is driven by these factors.

Of the three factors, only proximity to a subway, defined as the negative distance from the block centroid to the nearest subway stop, predicts post-1995 improvements in public safety (column 2). Although the standard errors are large, initial poverty rate and proximity to public housing do not appear correlated with late-1990s improvements in Cambridge public safety. Since heat maps of criminal activity in Cambridge appear strongest around neighborhoods closest to subway stops, this variable could capture proportional decreases in crime resulting in larger decreases in levels in these areas. In contrast, proximity to public housing enters with the wrong sign to be able to account for the RCI $\times$ Post effect in column 1. In columns 3, 7, and 11, we include each factor along with $\mathrm{RCI} \times$ Post; the $\mathrm{RCI} \times$ Post coefficient declines only slightly relative to column 1 and in an statistically insignificant manner. The coefficient on proximity to the nearest subway stop, however, is small and insignificant in column 3, suggesting that its importance in column 2 is driven by the positive correlation between RCI and subway access. The RCI $\times$ Post coefficients continue to be statistically significant even after controlling for an interaction between $\mathrm{RCI} \times$ Post and each factor, shown in columns 4, 8, and 12. Finally, controlling for interactions with initial crime levels, the main RCI $\times$ Post variable continues to be important in explaining crime declines in all but the case of public housing, although in this case, RCI still has a large effect - the post-period interaction between initial crime and rent control intensity is largest in column 9. At the same time, each of these factors does interact strongly with initial crime, thereby suggesting proximity to a subway station, proximity to public housing, and initial poverty rate all play a role in understanding crossneighborhood heterogeneity in 1990s crime trends. Overall, this analysis weighs against the idea that rent control exposure largely proxies for other aspects of neighborhood quality that changed discontinuously with the 1995 reform. 


\section{The Economic Value of Reduced Crime}

How valuable was the improved public safety that accompanied the post-rent-control gentrification of Cambridge in the late 1990s? In this section, we estimate how many fewer crimes occurred in Cambridge because rent control ended and then use criminology estimates of the welfare losses associated with criminal activity to provide a sense of public safety's importance. It is worth noting that we cannot use the hedonic approach in Autor et al. (2014) to value the improvements in public safety because the end of rent control affected property values in many different ways - inducing capital improvements and residential gentrification, and of course, permitting higher rents. By using cost-of-crime estimates from external sources, we decompose the fraction of rent deregulation's total effect, as measured by the aggregate change in property values, that is attributable to changes in public safety.

\subsection{Crimes Averted by Rent Decontrol}

In Table 9, we estimate the total number of crimes averted in the post period due to the removal of rent control. In panel A, we use estimates from our preferred specification in equation (3) (with linear tract trends as in panel B of Table 4). In panel B, we employ our most stringent empirical specification in equation (4), which controls for initial crime levels interacted with RCI ${ }^{16}$ We model the counterfactual level of total crimes per area that would have happened without the 1995 deregulation of Cambridge's rental market by turning off the RCI $\times$ Post term (and Initial Crime $\times$ RCI $\times$ Post term where applicable) ${ }^{17}$ The average annual number of averted crimes from 1995-2005 is then given by

$$
\Delta \widehat{\text { Crimes }}=\sum_{g} \hat{\beta}_{1} \mathrm{RCI}_{g} \text { Area }_{g}+\hat{\beta}_{2} \mathrm{RCI}_{g} \text { Area }_{g} \text { Initial Crime }_{g},
$$

where we sum the annual estimates over each year of the post period and each adjusted block. We also multiply the coefficient estimates by the area of each adjusted block to convert our estimates from estimated effects on crimes per 1,000 square meters to estimates of the total number of crimes averted. Because both the treatment effects and the costs of crime vary significantly across crime categories, we estimate $\beta_{1}$ and $\beta_{2}$ separately for each type of crime as in Table 7 .

Column 1 of Table 9 reports the annual number of averted crimes for each category for both specifications. For each crime category, the specification controlling for initial crimes provides more conservative estimates of the effect of decontrol-induced gentrification. Although this approach may be overfitting - if part of the reason high initial crime areas had the fastest decline in crime was their heavy exposure to rent control - we take these estimates to be a lower bound on rent decontrol's total effect on Cambridge public safety. Focusing on our more conservative specification, we estimate that

\footnotetext{
${ }^{16}$ To ensure comparability of estimates in panels A and B, we estimate this specification for years 1993-2005, as the specification in panel B requires using initial conditions measures from 1992 and drops that year.

${ }^{17}$ Note that we leave the Initial Crime $\times$ Post term as a way of allowing for proportional reductions in criminal activity that would have happened anyway.
} 
rent decontrol and the resulting gentrification led to almost 1,200 fewer crimes to being reported in Cambridge each year. The panel A estimated total number of averted crimes using tract trends has a smaller standard error than the estimates controlling for interactions with initial crime levels in panel B, although even the panel B estimate is statistically significant. Much of this reduction came from averted public disturbances and property crimes, by far the two most frequent types of crime in Cambridge. Our estimates also show meaningful decreases in other crime categories, including violent crimes, a particularly costly category of crime, as discussed below.

\subsection{Valuing Crime Reductions}

An extensive literature in both criminology and economics quantifies the relative significance of various crime types using a variety of methods to value avoiding exposure to crime. Prominent approaches include contingent valuation methods (e.g., Cohen, Rust, Steen and Tidd, 2004); hedonic regressions of property values on local crime rates; accounting measures including tangible and intangible quality-of-life costs (Miller et al., 1996); and inference based on the size of jury awards (e.g., Cohen, 1988).

We use crime cost estimates from Cohen and Piquero (2009), which is an updated version of a frequently-cited Department of Justice report by Miller et al. (1996) and offers two cost of

crime estimates. First, an accounting approach considers components of crime's direct costs to the victim and the criminal justice system, as well as the offender's lost wages while incarcerated. An alternative willingness-to-pay (WTP) approach tries to incorporate several important intangibles such as the externality crime imposes on those not directly victimized, e.g., the fear, stress, and costly avoidance behavior undertaken by potential victims.

Appendix Table A2 shows how we adapted the Cohen and Piquero (2009) estimates for our purposes. For each cost category, we take the weighted average of the Cohen and Piquero (2009) cost estimates across all crime types in each of our five main crime categories (e.g., the examples of each category listed in Section 3.1), weighted by the relative frequency of each crime category subcomponent in our Cambridge microdata. There is significant crime cost variation across categories, with victimization costs ranging from $\$ 1,291$ (in 2008 dollars) for public disturbance to over $\$ 47,000$ for a typical violent crime. Taking the frequency-weighted average of cost across all crime categories, the typical crime incident has a direct cost of $\$ 9,711$ and a WTP cost of $\$ 23,170$.

To quantify the value of the criminal activity reductions that we estimate are attributable to neighborhood change resulting from the end of rent control in Cambridge, we multiply the number of averted crimes in column 1 of Table 9 by various cost estimates from Table 9 . Importantly for understanding the economic value of these crime reductions, we estimate that around 77 fewer violent crimes - which are particularly costly for both victims and communities - would have occurred each year. Despite the relatively small number of averted violent crimes, their severity makes them the most consequential category of public safety improvement, so that the reduction in violent crimes alone raises the welfare of potential victims by $\$ 4$ million annually, a fact shown in column 2 .

Total Direct Cost, shown in column 5, sums the Victimization Costs, Criminal Justice System 
Costs, and Offender Productivity Costs. Column 5 in panel B shows that the end of rent control eliminated $\$ 9.8$ million in annual economic costs due to crime in Cambridge. Assuming this flow is permanent, which is consistent with the event studies in Figure 5 that show little sign of reversion, we capitalize this annual flow at a 5\% discount rate. This amounts to a $\$ 196$ million increase in Cambridge's aggregate value, and this increase should be reflected in the aggregate property value of Cambridge residential real estate. Using the Autor et al. (2014) estimate that by 2005 total property values had increased by approximately $\$ 2$ billion because of the end of rent control, we find that approximately $10 \%$ of this increase in aggregate value was due to improved public safety.

As discussed above, the Cohen and Piquero (2009) total direct cost of crime estimates do not capture the social cost of crime, such as the burden of fear and avoidance caused by crime proximity. Using Willingness-to-Pay (WTP) to avoid crime captures this effect and provides a likely upper bound on the economic value created in Cambridge via the crime reductions shown in Table 9. By applying these avoidance WTP cost estimates and capitalizing the annual flows into stocks at a $5 \%$ discount rate, we estimate the improved public safety engendered by the late-1990s gentrification in Cambridge spurred by the end of rent control in 1995 has a present-discounted value of $\$ 444$ million, shown in panel B column 8. When we divide these estimates by rent deregulation's total effect on Cambridge property values estimated in Autor, Palmer, and Pathak (2014), we estimate that improved public safety is responsible for $22 \%$ of overall property-value appreciation.

Table 10 presents a direct way to compare rent decontrol's effects on property values versus the direct costs of crime. We report estimates of the effect of rent decontrol on property values and the costs of crime from difference-in-difference models fit at the block-year level with year and block fixed effects. Property values are the sum of assessed values from the 1994 and 2002 Cambridge Assessor's file, used in Autor et al. (2014). The total direct cost of crime is the cost of all crimes in the block-year valued using the Cohen and Piquero (2009) cost estimates. Since the value of crime averted is annual, we convert crime effect into a stock using a 5\% discount rate. About 15\% of the property price increase in Cambridge due to rent decontrol can be attributed to the value of averted crime. Moreover, the WTP to avoid crime represents $34 \%$ of the property price increase in Cambridge due to rent control.

The estimates reported in Panel A monetize the four crime categories - property crime, public disturbance, drugs and alcohol, and violent crime - directly. Cohen and Piquero (2009) also report a finer categorization of crimes consisting of 14 categories (in their Table 5) that we can use to calculate the costs of crime. Furthermore, since violent crimes have the highest total direct cost and are relatively infrequent, we separately report estimates for only non violent crimes. Panel B of Table 10 shows that our estimate of the total costs associated with non-violent crimes is similar using either the coarse or fine categories. They represent about $5-6 \%$ of the total value of price appreciation due to rent decontrol. The estimate for violent crime, on the other hand, is much more sensitive to the categorization method. Using the coarse categorization, the cost of violent crimes is $10 \%$ of the total value of price appreciation. Under the fine categorization, it is noisily estimated.

The monetized value of crime reductions should be less than the total value of price appreciation 
due to rent decontrol, since Cambridge properties experienced investment upgrades and an influx of new residents. Autor et al. (2014) conclude that additional investment activity could in the best case scenario explain 12 percent of the appreciation of Cambridge residential properties. This leaves the remaining 88 percent accounted for by other benefits of rent decontrol. Given this upper bound, the results in Table 9 and 10 indicate that the cost of crime estimates in Cohen and Piquero (2009) are not beyond what would be expected given the overall aggregate price change.

\section{Conclusion}

We use the abrupt and arguably unanticipated end of rent control in Cambridge, Massachusetts, combined with rich geocoded incident-level crime data and plausibly-exogenous block-level variation in exposure to gentrification, to identify how the late-1990s neighborhood changes in Cambridge affected criminal activity. In the years immediately following the elimination of Cambridge's rent regulation by a November 1994 state ballot initiative, Cambridge neighborhoods changed. This gentrification process lowered crime in Cambridge by an estimated 16\%. Property crimes account for the largest decrease in the number of reported criminal incidents, while violent crimes account for the bulk of the value in averted crimes. Since the value of price appreciation due to rent decontrol provides an upper bound on how much Cambridge resident's value improvements in public safety, our paper establishes that the estimates of the cost of crime in Cohen and Piquero (2009) are within the bounds imposed by the aggregate price appreciation due to rent decontrol, even netting out the possible direct benefits of additional investments in Cambridge properties.

How economically significant is a crime decrease of this magnitude? Applying cost-of-crime estimates from the criminology literature, we estimate this improvement in public safety created between $\$ 10-22$ million a year (in 2008 dollars) of benefit to the city. For context, Cambridge residential property values appreciated by a total of $\$ 7.8$ billion from 1994-2005, $\$ 2$ billion of which is directly attributable to the end of rent control (see Autor, Palmer, and Pathak, 2014). By calculating the present discounted value of a $\$ 10$ or $\$ 22$ million annual flow, we estimate that between $10-22 \%$ of the increased aggregate value due to rent deregulation was a direct result of decreased crime. Improvements in public safety are therefore an economically significant part of the gentrification process and are of comparable economic magnitude to the value of additional property investments. 


\section{References}

Aliprantis, Dionissi and Daniel Hartley, "Blowing it up and knocking it down: The local and city-wide effects of demolishing high concentration public housing on crime," Journal of Urban Economics, 2015, 88, 67-81.

Andersson, Tommy and Lars-Gunnar Svensson, "Non-Manipulable House Allocation With Rent Control," Econometrica, 2014, 82 (2), 507-539.

Autor, David H, Christopher J Palmer, and Parag A Pathak, "Housing Market Spillovers: Evidence for the End of Rent Control in Cambridge, Massachusetts," Journal of Political Economy, 2014, 122 (3), 661-717.

Bajari, Patrick and C. Lanier Benkard, "Demand Estimation with Heterogenous Consumers and Unobserved Product Characteristics: A Hedonic Approach," Journal of Political Economy, 2005, 113(6), 1239-1276.

Bartik, Timothy J., "The Estimation of Demand Parameters in Hedonic Price Models," Journal of Political Economy, 1987, 95(1), 81-88.

Bishop, Kelly C. and Alvin D. Murphy, "Estimating the Willingness to Pay to Avoid Violent Crime: A Dynamic Approach," American Economic Review, Papers and Proceedings, 2011, 101(3), 625-629.

Black, Sandra, "Do Better Schools Matter? Parental Valuation of Elementary Education," Quarterly Journal of Economics, 1999, 114(2), 577-599.

Bowes, David R and Keith R Ihlanfeldt, "Identifying the Impacts of Rail Transit Stations on Residential Property Values," Journal of Urban Economics, 2001, 50 (1), 1-25.

Carpenter, Christopher and Carlos Dobkin, "The minimum legal drinking age and public health," Journal of Economic Perspectives, 2011.

Chay, Kenneth Y. and Michael Greenstone, "Does Air Quality Matter? Evidence from the Housing Market," Journal of Political Economy, 2005, 113(2), 376-424.

City of New York Police Department, "New York City Crime Map Statistical and Technical Notes," May 2015.

Cohen, Mark A., "Some New Evidence on the Seriousness of Crime," Criminology, 1988, 26(2), 343-353.

Cohen, Mark A and Alex R Piquero, "New Evidence on the Monetary Value of Saving a High Risk Youth," Journal of Quantitative Criminology, 2009, 25 (1), 25-49. 
_ Roland T. Rust, Sara Steen, and Simon T. Tidd, "Willingness-to-Pay for Crime Control Programs," Criminology, 2004, 42(1), 89-110.

Conley, Timothy G, "GMM estimation with cross sectional dependence," Journal of Econometrics, 1999, 92 (1), 1-45.

Covington, Jeanette and Ralph B Taylor, "Gentrification and Crime: Robbery and Larceny Changes in Appreciating Baltimore Neighborhoods during the 1970s," Urban Affairs Review, 1989, 25 (1), 142-172.

Cullen, Julie Berry and Steven D Levitt, "Crime, urban flight, and the consequences for cities," Review of economics and statistics, 1999, 81 (2), 159-169.

Dahl, Gordon and Stefano DellaVigna, "Does movie violence increase violent crime?," Quarterly Journal of Economics, 2009, 124(2), 677-734.

Deming, David J., "Better schools, less crime?," Quarterly Journal of Economics, 2011, pp. 20632115 .

Diamond, Rebecca, Tim McQuade, and Franklin Qian, "The Effects of Rent Control Expansion on Tenants, Landlords, and Inequality: Evidence from San Francisco," July 2017. Working Paper.

Ellen, Ingrid Gould, Johanna Lacoe, and Claudia Ayanna Sharygin, "Do Foreclosures Cause Crime?," Journal of Urban Economics, 2013, 74, 59-70.

_ _ Keren Horn, and David Reed, "Has Falling Crime Invited Gentrification?," March 2017. US Census Bureau Center for Economic Studies Paper No. CES-WP-17-27. Available at SSRN: https://ssrn.com/abstract=2930242.

Epple, Dennis, "Hedonic Prices and Implicit Markets: Estimating Demand and Supply Functions for Differentiated Products," Journal of Political Economy, 1987, 95(1), 59-80.

Farrell, Graham, Nick Tilley, Andromachi Tseloni, and Jen Mailley, "The crime drop and the security hypothesis," Journal of Research in Crime and Delinquency, 2011, 48 (2), 147-175.

Fetter, Daniel K, "The Home Front: Rent control and the rapid wartime increase in home ownership," The Journal of Economic History, 2016, 76 (4), 1001-1043.

Gibbons, Steve, "The Costs of Urban Property Crime," Economic Journal, 2004, 113, F441-462.

Guerrieri, Veronica, Daniel Hartley, and Erik Hurst, "Endogenous gentrification and housing price dynamics," Journal of Public Economics, 2013, 100, 45-60.

Hausman, Jerry A., Bronwyn H. Hall, and Zvi Griliches, "Econometric Models for Count Data with an Application to the Patents-R\&D Relationship," Econometrica, 1984, 52(4), 909938. 
Heckman, James J. and D. Masterov, "The Productivity Argument for Investing in Young Children," 2007. NBER Working Paper 13016.

Hilber, Christian A. L., "The Economic Implications of House Price Capitalization: A Synthesis," Real Estate Economics, 2017, 45 (2), 301-339.

Ihlanfeldt, Keith and Tom Mayock, "Panel data estimates of the effects of different types of crime on housing prices," Regional Science and Urban Economics, 2010, 40 (2), 161-172.

Isen, Adam, Maya Rossin-Slater, and Reed Walker, "Every Breath you Take - Every Dollar You'll Make: The Long-Term Consequences of the Clean Air Act of 1970," Journal of Political Economy, 2017, pp. 848-902.

Kling, Jeffrey R, Jens Ludwig, and Lawrence F Katz, "Neighborhood Effects on Crime for Female and Male Youth: Evidence from a Randomized Housing Voucher Experiment," The Quarterly Journal of Economics, February 2005, 120 (1), 87-130.

Lee, Yan Y, "Gentrification and Crime: Identification Using the 1994 Northridge Earthquake in Los Angeles," Journal of Urban Affairs, 2010, 32 (5), 549-577.

Linden, Leigh and Jonah Rockoff, "Estimates of the Impacts of Crime Risk on Property Values from Megan's Laws," American Economic Review, 2008, 98(3), 1103-1127.

Lochner, Lars and Enrico Moretti, "The effect of education on crime: Evidence from prison inmates, arrests, and self-reports," American Economic Review, 2004, 94(1), 155-189.

McDonald, Scott C, "Does gentrification affect crime rates," Crime \& Justice, 1986, 8, 163-201.

Miller, Ted R, Mark A Cohen, and Brian Wiersema, "Victim costs and consequences: A new look," Research Report, US Department of Justice, Office of Justice Programs, National Institute of Justice 1996.

Papachristos, Andrew V, Chris M Smith, Mary L Scherer, and Melissa A Fugiero, "More Coffee, Less Crime? The Relationship between Gentrification and Neighborhood Crime Rates in Chicago, 1991 to 2005," City $\&$ Community, 2011, 10 (3), 215-240.

Pope, Devin G. and Jaren C. Pope, "Crime and property values: Evidence from the 1990s crime drop," Regional Science and Urban Economics, 2012, 42(1-2), 177-188.

Pope, Jaren, "Fear of Crime and Housing Prices: Household Reactions to Sex Offender Registries," Journal of Urban Economics, 2008, 64(3), 601-614.

Sampson, Robert J, Stephen W. Raudenbush, and Felton Earls, "Neighborhoods and Violent Crime: A Multilevel Study of Collective Efficacy," Science, 1997, 277 (5328), 918-924.

Sims, David P., "Out of Control: What can we learn from the end of Massachusetts rent control?," Journal of Urban Economics, 2007, 61(1), 129-151. 
_ _ "Rent Control Rationing and Community Composition: Evidence from Massachusetts," The B.E. Journal of Economic Analysis \& Policy, 2011, 11(1).

Sullivan, Daniel M., "The True Cost of Air Pollution: Evidence from the Housing Market," March 2017. Working Paper.

Taylor, Ralph B and Jeanette Covington, "Neighborhood Changes in Ecology and Violence," Criminology, 1988, 26 (4), 553-590.

Thaler, Richard, "A Note on the Value of Crime Control: Evidence from the Property Market," Journal of Urban Economics, 1978, 5(1), 137-145.

Vigdor, Jacob L, "Locations, outcomes, and selective migration," Review of Economics and Statistics, 2002, 84 (4), 751-755.

Weisburd, David L, Elizabeth R Groff, and Sue-Ming Yang, The Criminology of Place: Street Segments and Our Understanding of the Crime Problem, Oxford University Press, 2012.

Wilsem, Johan Van, Karin Wittebrood, and Nan Dirk De Graaf, "Socioeconomic Dynamics of Neighborhoods and the Risk of Crime Victimization: A Multilevel Study of Improving, Declining, and Stable Areas in the Netherlands," Social Problems, 2006, 53 (2), 226-247.

Wilson, James Q and George L Kelling, "Broken Windows," The Atlantic Monthly, March 1982, pp. 29-38.

Wilson, William Julius, The Truly Disadvantaged: The Inner City, the Underclass, and Public Policy, University of Chicago Press, 1987. 
Figure 1: Heat Map of Cambridge Adjusted Blocks

A. By Rent Control Intensity

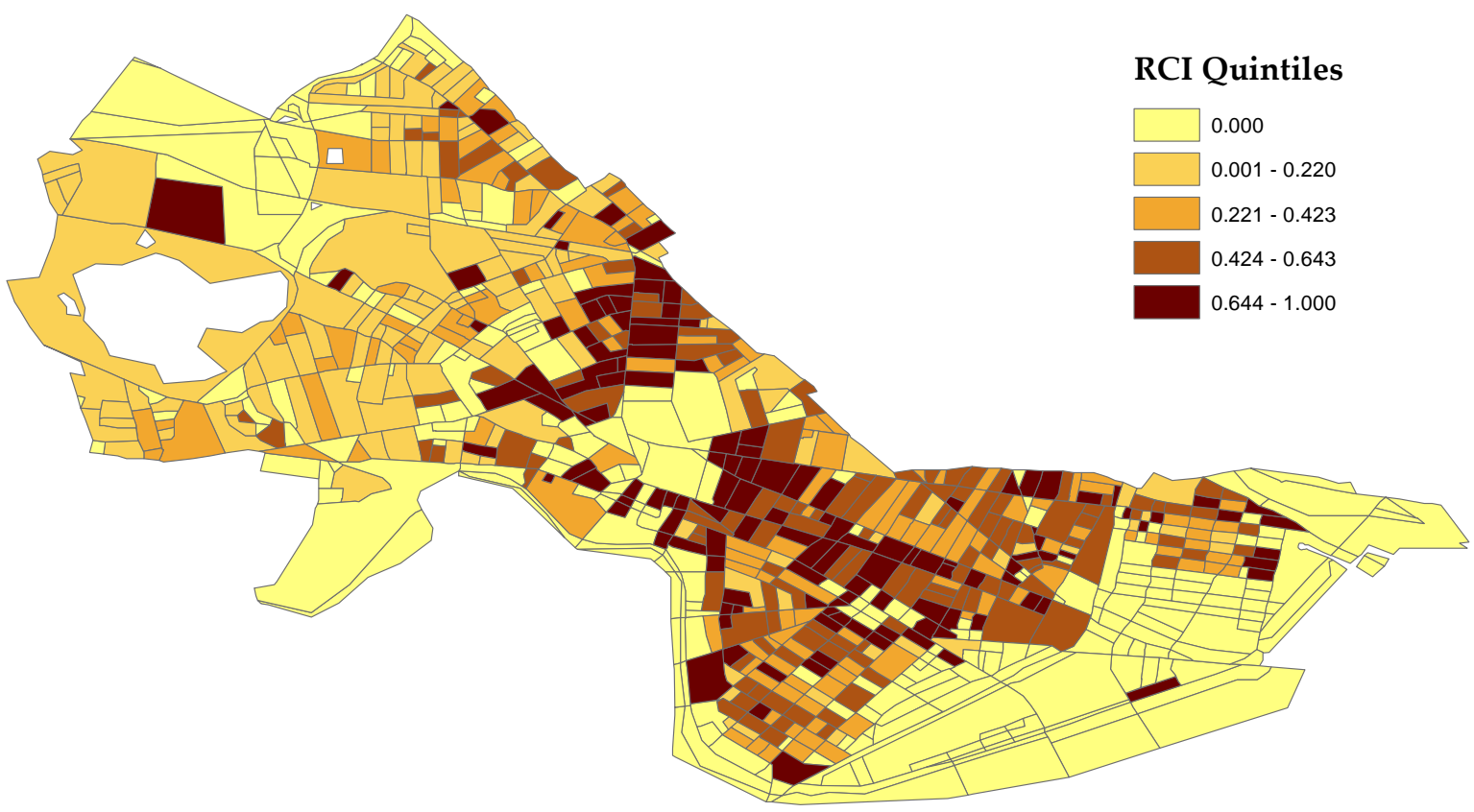

B. By Average Crimes, 1992-2005

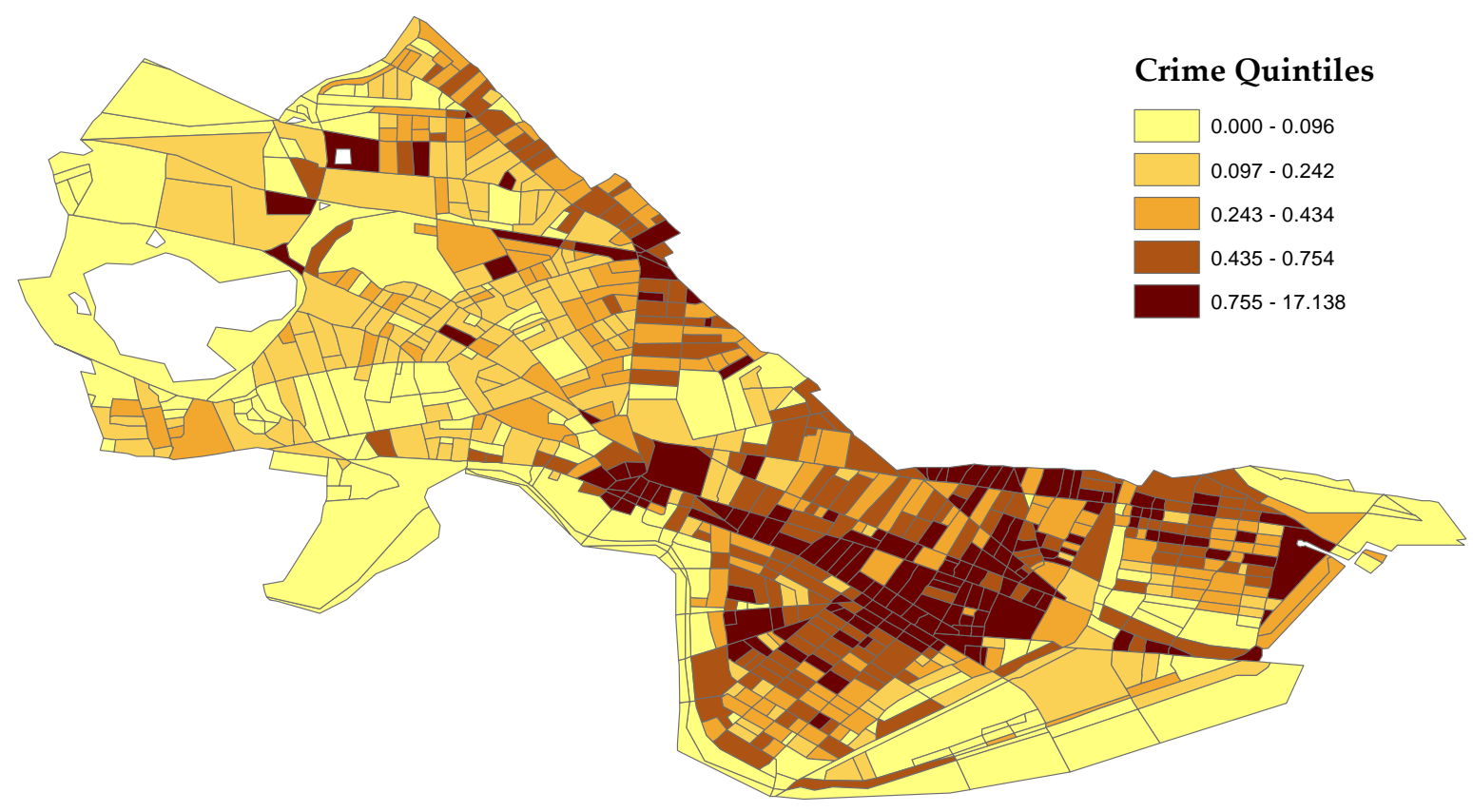


Figure 2: Trends in Cambridge Crime by Category, 1992-2005

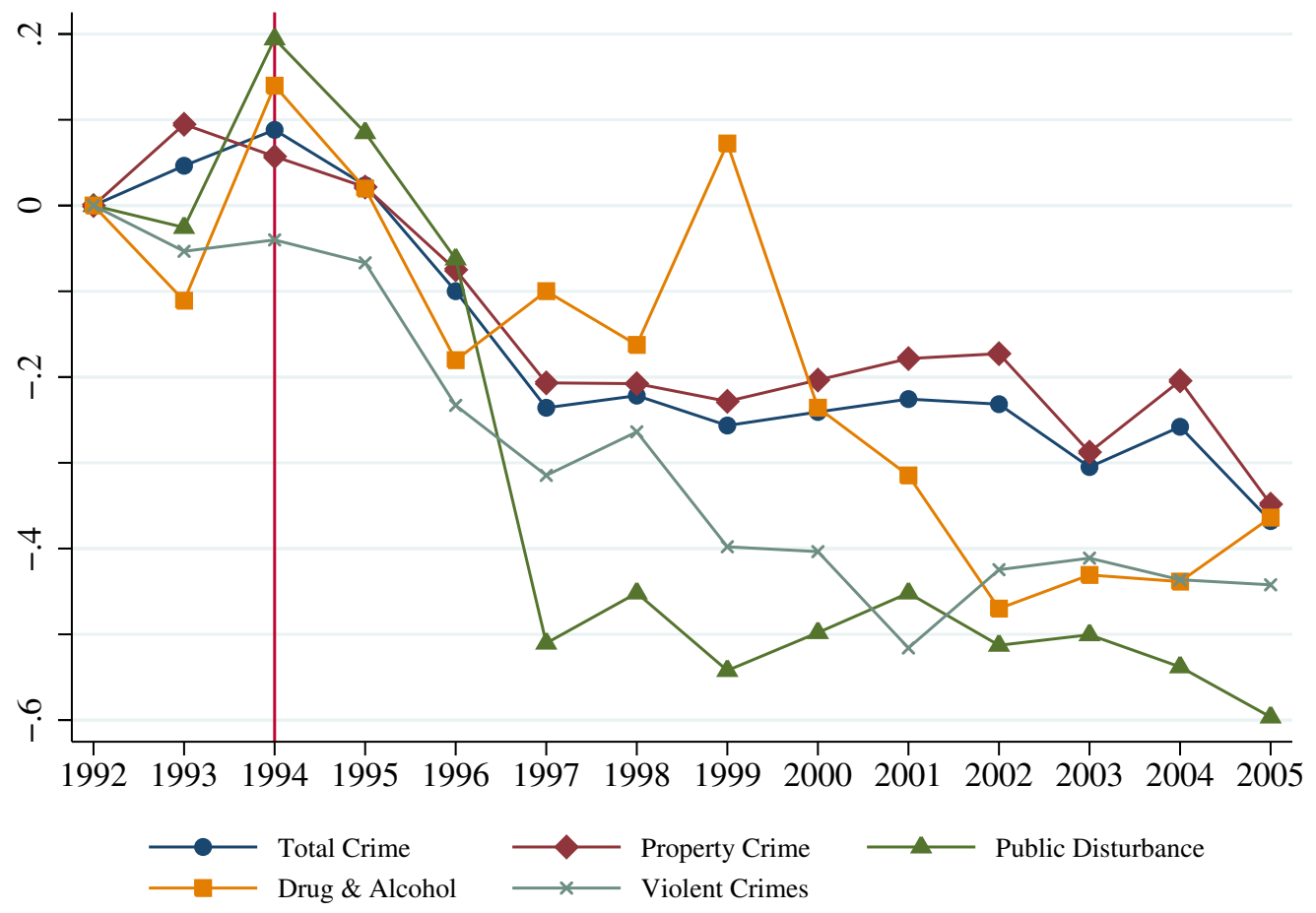

Notes: Graph plots log counts of crimes in our Cambridge data by category for each year before geocoding. The vertical line at 1994 indicates the last year of rent control regulations. 
Figure 3: Distribution of Simulated Coefficients

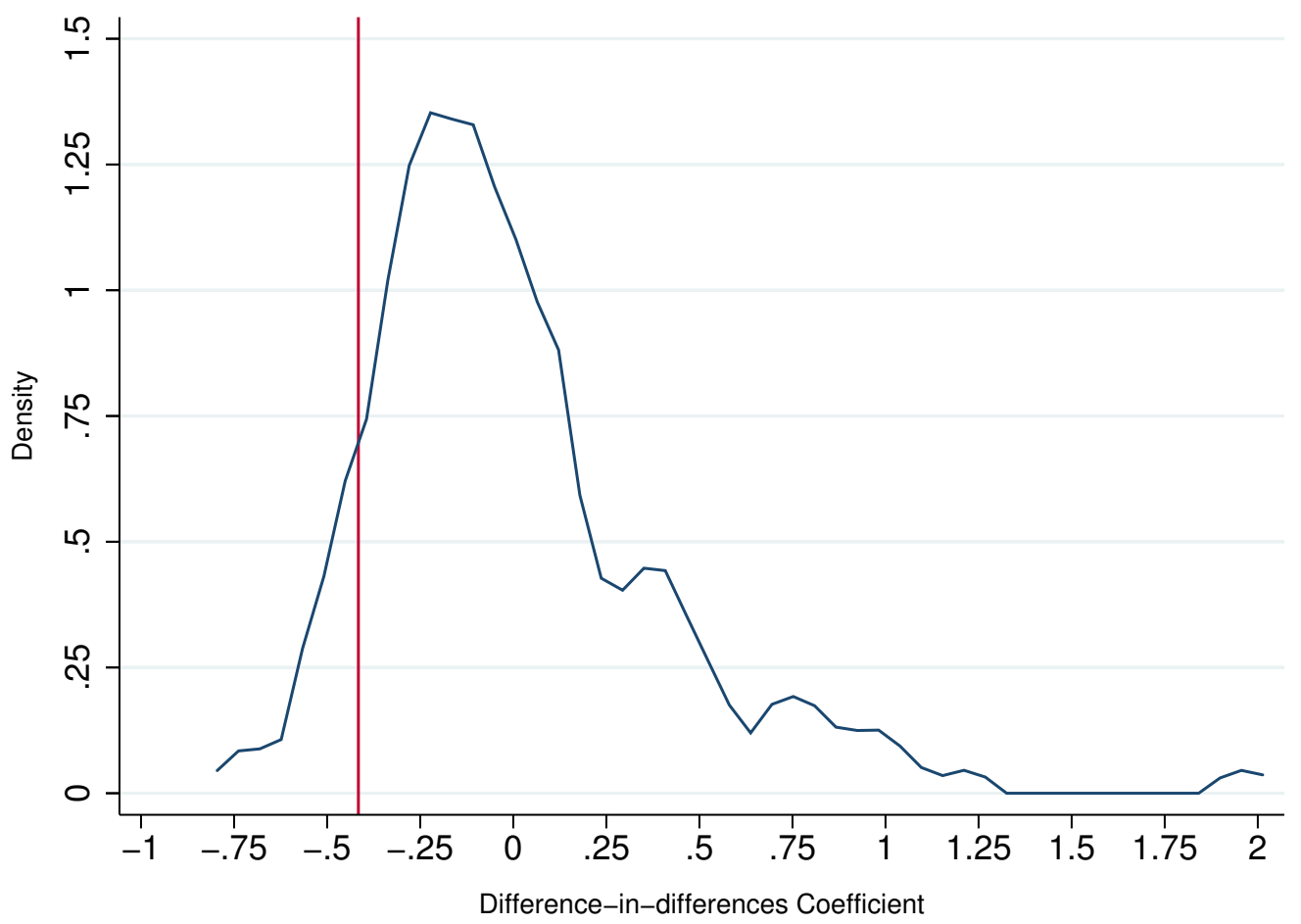

Notes: Graph plots the kernel density distribution of coefficients from regressions of log total crime on city $\mathrm{x}$ post treatment interactions for each city as reported in UCR. The sample includes 147 cities with populations of $75 \mathrm{~K}-150 \mathrm{~K}$ in at least one year from 1985 to 2012 . Cambridge is at 8.84 percentile of log total crime variable. Bandwidth for kernel is 0.05 . 
Figure 4: Adjusted Block Group Boundaries Examples
A. Census Blocks
B. Adjusted Blocks
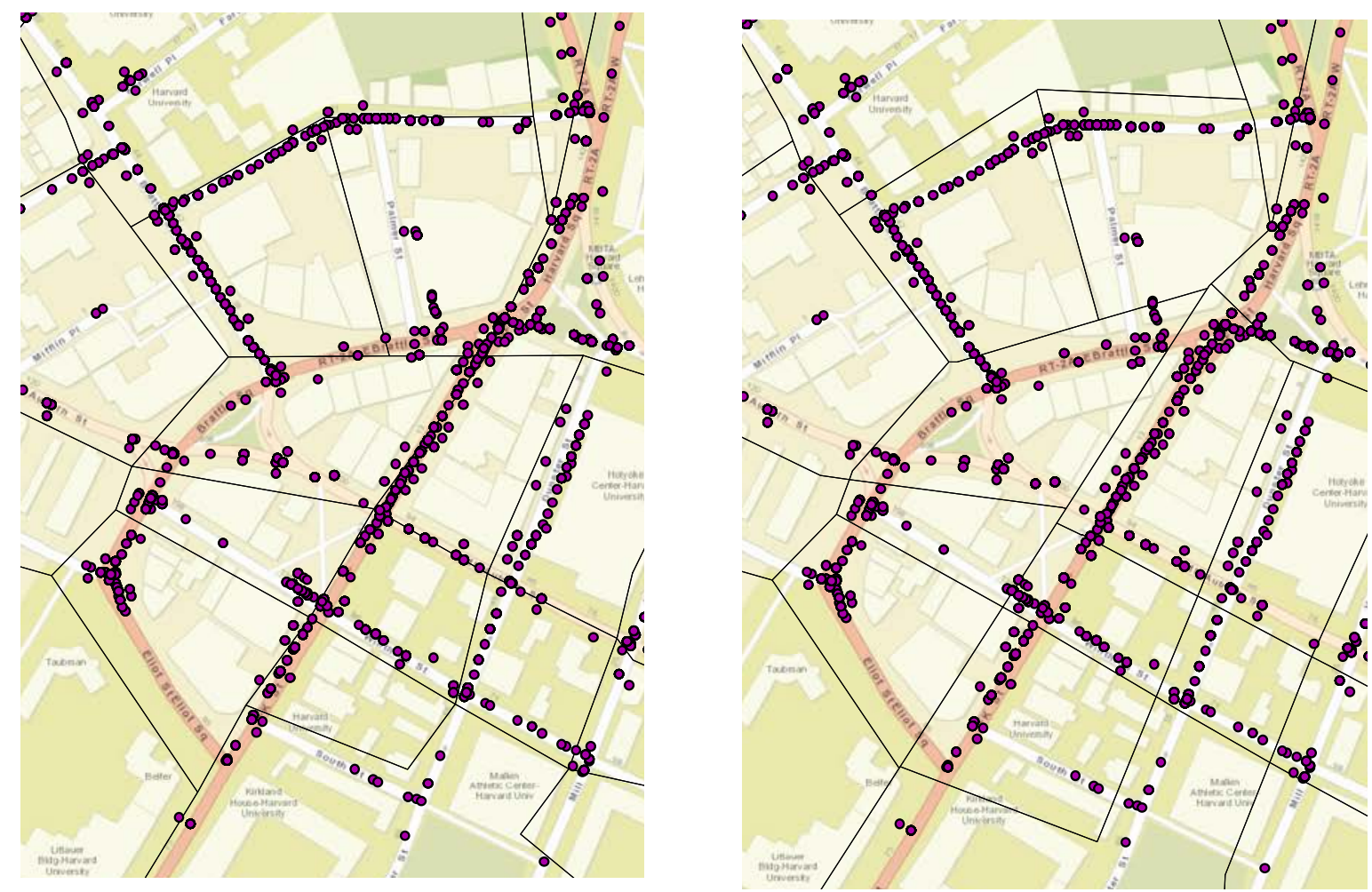

Notes: The figures plot geographies of Harvard Square, Cambridge, Massachusetts. Crime events are marked with purple circles. Figure A is overlaid with Census 1990 Block Boundaries, and Figure $\mathrm{B}$ is overlaid with adjusted Census blocks in which boundaries are moved away from the street center lines. Blue and red squares show instances where adjusted block boundaries ensure the crime events that happen nearby are assigned to the same geographical unit. The adjusted blocks can also be seen as blockfaces, street segment bounded by the two closest cross-streets as in Ellen et al. (2013), merged to mimic the size of the Census blocks. 
Figure 5: Event Study of Effect of RCI on Total Crimes per $1,000 \mathrm{~m}^{2}$

A. Without Linear Census Tract Trend Controls

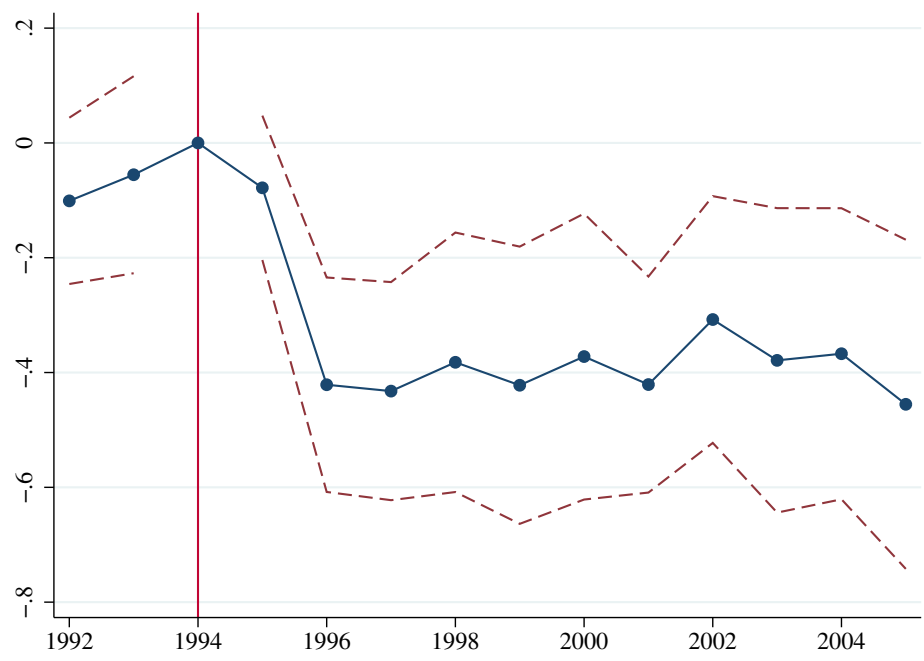

B. With Linear Census Tract Trend Controls

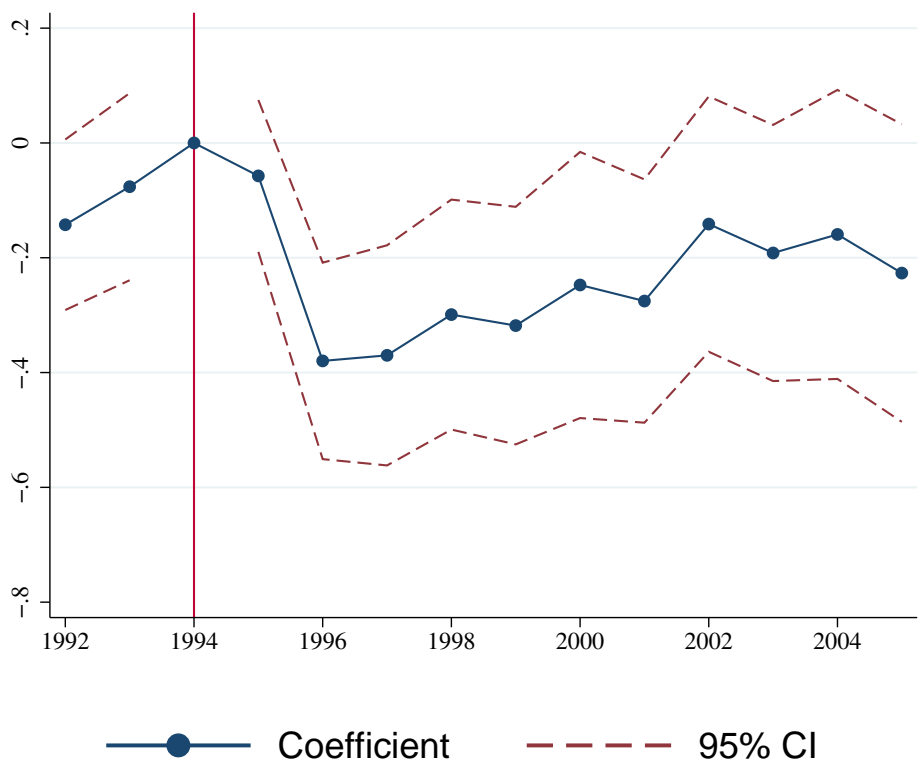

Notes: Figure plots event study coefficients for the effect of Rent Control Intensity (RCI) on total crime per area, 1992-2005. RCI measures the intensity with which a block was exposed to rent controlled properties prior to 1995. The figures plot coefficients on RCI x Year variables from eventstudy regressions in which the dependent variable is total crime per $1,000 \mathrm{~m}^{2}$. The specification includes year and block fixed effects, and panel B also includes linear Census tract trends. The year 1994 is the omitted RCI x Year category. Robust standard errors are clustered by block level. The vertical line 1994 indicates the year preceding rent decontrol. 
Figure 6: Predicted Effect of Rent Control Intensity and Initial Crime on Total Crime per 1,000m²

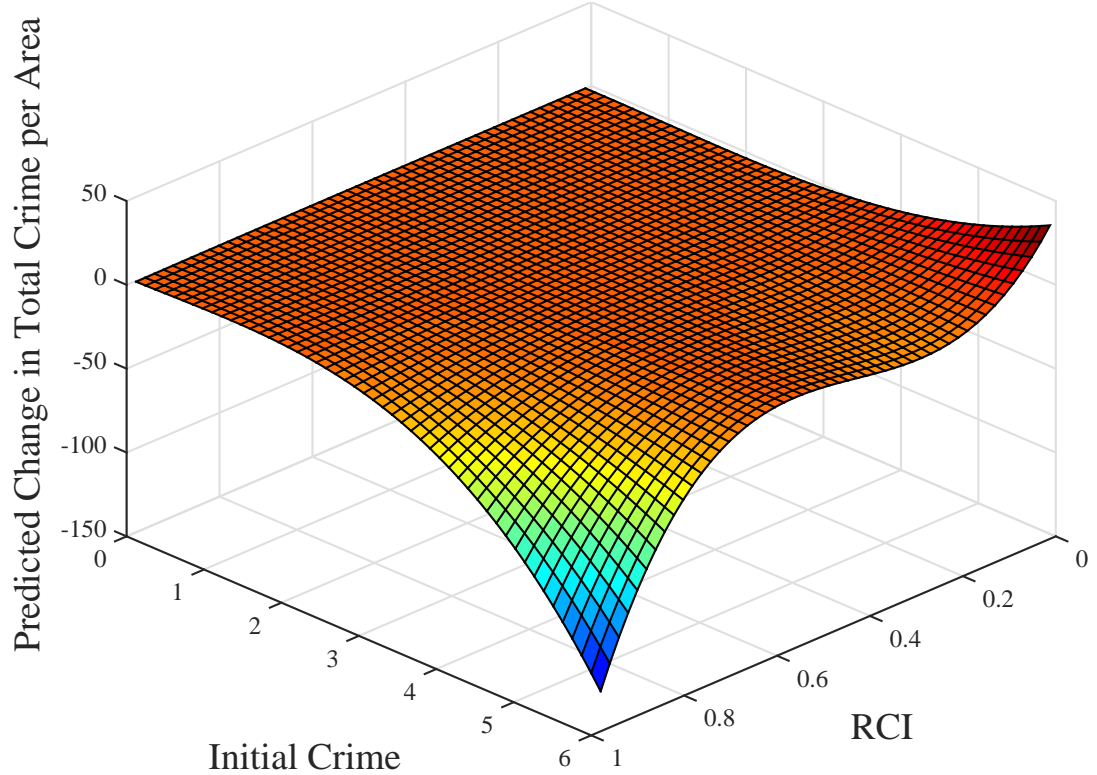

Notes: Predicted effect of RCI $(\lambda=12)$ and initial crime on total crime per area. RCI measures the intensity of an adjusted block's exposure to rent-controlled properties prior to 1995. The figure plots, for each level of RCI and IC, the sum of predicted values of interaction variables that are combinations of RCI, (RCI $)^{2}$, (RCI $)^{3}$, Initial Crime, (Initial Crime) ${ }^{2}$, (Initial Crime) $)^{3}$, all of which are interacted with post treatment indicator dummy. The dependent variable is total crime per $1,000 \mathrm{~m}^{2}$. The specification includes year and block fixed effects. 
Table 1: Descriptive Statistics on Demographics

\begin{tabular}{|c|c|c|c|c|c|c|}
\hline & $\begin{array}{c}1990 \\
(1) \\
\end{array}$ & $\begin{array}{c}2000 \\
(2) \\
\end{array}$ & $\begin{array}{c}\text { Difference } \\
\text { (3) }\end{array}$ & & $\begin{array}{c}\text { RCI x Pos } \\
\text { (4) }\end{array}$ & \\
\hline Population & 3193 & 3379 & $\begin{array}{l}185 \\
(356)\end{array}$ & & $\begin{array}{l}-203 \\
(299)\end{array}$ & \\
\hline Share White & .765 & .694 & $\begin{array}{l}-.070 \\
(.039)\end{array}$ & * & $\begin{array}{l}-.004 \\
(.053)\end{array}$ & \\
\hline Share Black & .138 & .121 & $\begin{array}{l}-.017 \\
(.030)\end{array}$ & & $\begin{array}{l}-.026 \\
(.028)\end{array}$ & \\
\hline Share Other Races & .097 & .185 & $\begin{array}{l}.088 \\
(.017)\end{array}$ & $* * *$ & $\begin{array}{l}.030 \\
(.043)\end{array}$ & \\
\hline Share Juveniles & .062 & .055 & $\begin{array}{l}-.008 \\
(.015)\end{array}$ & & $\begin{array}{l}-.048 \\
(.019)\end{array}$ & $* * *$ \\
\hline Share Income $<\$ 30 \mathrm{~K}$ & .420 & .304 & $\begin{array}{l}-.116 \\
(.026)\end{array}$ & $* * *$ & $\begin{array}{l}-.069 \\
(.045)\end{array}$ & \\
\hline Share $\$ 30 \mathrm{~K} \leq$ Income $<\$ 60 \mathrm{~K}$ & .303 & .263 & $\begin{array}{l}-.041 \\
(.014)\end{array}$ & $* * *$ & $\begin{array}{l}-.016 \\
(.045)\end{array}$ & \\
\hline Share $\$ 60 \mathrm{~K}>$ Income & .210 & .390 & $\begin{array}{l}.179 \\
(.028)\end{array}$ & $* * *$ & $\begin{array}{l}.058 \\
(.056)\end{array}$ & \\
\hline Share Less than College & .450 & .335 & $\begin{array}{l}-.115 \\
(.050)\end{array}$ & $* *$ & $\begin{array}{l}.089 \\
(.056)\end{array}$ & \\
\hline Share College Graduates & .264 & .296 & $\begin{array}{l}.032 \\
(.015)\end{array}$ & $* *$ & $\begin{array}{l}-.061 \\
(.058)\end{array}$ & \\
\hline Share Post College Graduates & .286 & .369 & $\begin{array}{l}.082 \\
(.038)\end{array}$ & $* *$ & $\begin{array}{l}-.029 \\
(.052)\end{array}$ & \\
\hline Share Services Occupation & .418 & .580 & $\begin{array}{l}.162 \\
(.038)\end{array}$ & $* * *$ & $\begin{array}{l}-.130 \\
(.122)\end{array}$ & \\
\hline Share Blue Collar Occupation & .128 & .10 & $\begin{array}{l}-.028 \\
(.019)\end{array}$ & & $\begin{array}{l}.036 \\
(.042)\end{array}$ & \\
\hline Share White Collar Occupation & .454 & 1.488 & $\begin{array}{l}1.034 \\
(.064)\end{array}$ & $* * *$ & $\begin{array}{l}.021 \\
(.177)\end{array}$ & \\
\hline Share Attending College & .201 & .192 & $\begin{array}{l}-.009 \\
(.044)\end{array}$ & & $\begin{array}{l}.070 \\
(.024)\end{array}$ & $* * *$ \\
\hline Housing Units & 1399 & 1491 & $\begin{array}{c}92 \\
(122)\end{array}$ & & $\begin{array}{l}-182 \\
(131)\end{array}$ & \\
\hline $\begin{array}{l}\text { Average Number of People in a } \\
\text { Housing Unit }\end{array}$ & .936 & .955 & $\begin{array}{l}.019 \\
(.008)\end{array}$ & $* *$ & $\begin{array}{l}-.020 \\
(.037)\end{array}$ & \\
\hline $\mathrm{N}$ & 30 & 30 & 60 & & 60 & \\
\hline
\end{tabular}


Table 2: Descriptive Statistics on Crime and Rent Control Intensity

\begin{tabular}{lccccr}
\hline & Mean & Median & Std. Dev. & Minimum & Maximum \\
\cline { 2 - 5 } & \multicolumn{4}{c}{ A. Crimes } & per Area by Category \\
Property Crime & 0.354 & 0.178 & 0.767 & 0.000 & 22.523 \\
Public Disturbance & 0.127 & 0.020 & 0.271 & 0.000 & 4.612 \\
Drug \& Alcohol & 0.015 & 0.000 & 0.063 & 0.000 & 1.241 \\
Violent Crime & 0.051 & 0.000 & 0.135 & 0.000 & 2.963 \\
Total Crime & 0.535 & 0.266 & 1.065 & 0.000 & 27.672 \\
\cline { 2 - 6 } & 0.439 & 0.467 & 0.110 & 0.149 & 0.604 \\
$\lambda=3$ & 0.404 & 0.426 & 0.191 & 0.012 & 0.980 \\
$\lambda=12$ & 0.396 & 0.405 & 0.218 & 0.000 & 1.000 \\
$\lambda=21$ & 0.392 & 0.397 & 0.233 & 0.000 & 1.000 \\
$\lambda=30$ & 0.296 & 0.218 & 0.308 & 0.000 & 1.000 \\
$\lambda \rightarrow \infty$ & \multicolumn{5}{c}{ B. Rent Control Intensity by $\lambda$} \\
\hline
\end{tabular}

Notes: Panel A reports summary statistics of crime counts by crime category per 1,000 square meters at the adjusted block by year level. Panel B reports summary statistics of Rent Control Intensity at the adjusted block level across values of the exponential decay weight $\lambda$. N $=11,424$ for Panel A, and N = 816 for Panel B. 
Table 3: Effect of Rent Control Intensity on Total Crimes Dependent Variable: Total Crimes per $1,000 \mathrm{~m}^{2}$

\begin{tabular}{|c|c|c|c|c|c|c|c|c|c|c|}
\hline Exponential Weight & $\begin{array}{c}\lambda=3 \\
(1)\end{array}$ & & $\begin{array}{c}\lambda=12 \\
(2)\end{array}$ & & $\begin{array}{c}\lambda=21 \\
(3)\end{array}$ & & $\begin{array}{c}\lambda=30 \\
(4)\end{array}$ & & $\begin{array}{c}\lambda=\infty \\
(5)\end{array}$ & \\
\hline RCI x Post & $\begin{array}{l}-.561 \\
(.170)\end{array}$ & $* * *$ & $\begin{array}{l}. \text { Specifi } \\
-.315 \\
(.095)\end{array}$ & $\frac{\text { tion }}{* * *}$ & $\begin{array}{c}\text { Without } \\
-.287 \\
(.094)\end{array}$ & $\frac{\text { ract }}{* * *}$ & $\begin{array}{c}\text { Trends } \\
-.278 \\
(.097)\end{array}$ & $* * *$ & $\begin{array}{l}-.267 \\
(.103)\end{array}$ & $* * *$ \\
\hline R-squared & .852 & & .852 & & .852 & & .852 & & .853 & \\
\hline Effect on crime of 1 s.d. RCI & $-11.48 \%$ & & $-11.25 \%$ & & $-11.67 \%$ & & $-12.11 \%$ & & $-15.40 \%$ & \\
\hline RCI x Post & $\begin{array}{l}-.405 \\
(.116)\end{array}$ & B** & $\begin{array}{l}\text { Specifica } \\
. .203 \\
(.062)\end{array}$ & $\frac{\text { ons }}{* * *}$ &  & $\begin{array}{l}\text { Trac } \\
* * *\end{array}$ & $\begin{array}{l}\mathrm{t} \text { Trends } \\
-.195 \\
(.065)\end{array}$ & $* * *$ & $\begin{array}{l}-.215 \\
(.088)\end{array}$ & $* *$ \\
\hline R-squared & .854 & & .854 & & .854 & & .854 & & .854 & \\
\hline Effect on crime of 1 s.d. RCI & $-8.29 \%$ & & $-7.25 \%$ & & $-7.92 \%$ & & $-8.47 \%$ & & $-12.39 \%$ & \\
\hline
\end{tabular}

Notes: $\mathrm{N}=11,424$. All specifications include year fixed effects and fixed effects for 816 adjusted Census blocks. Specifications in Panel B include linear trends for 30 Census tracts. Standard errors in parentheses clustered at the block level. Mean of the dependent variable is 0.557 , and the standard deviation is 1.051.

$* * * \mathrm{p}<0.01, * * \mathrm{p}<0.05, * \mathrm{p}<0.1$ 
Table 4: Effect of Rent Control Intensity on Crime Categories Dependent Variable: Reported Crimes per $1,000 \mathrm{~m}^{2}$

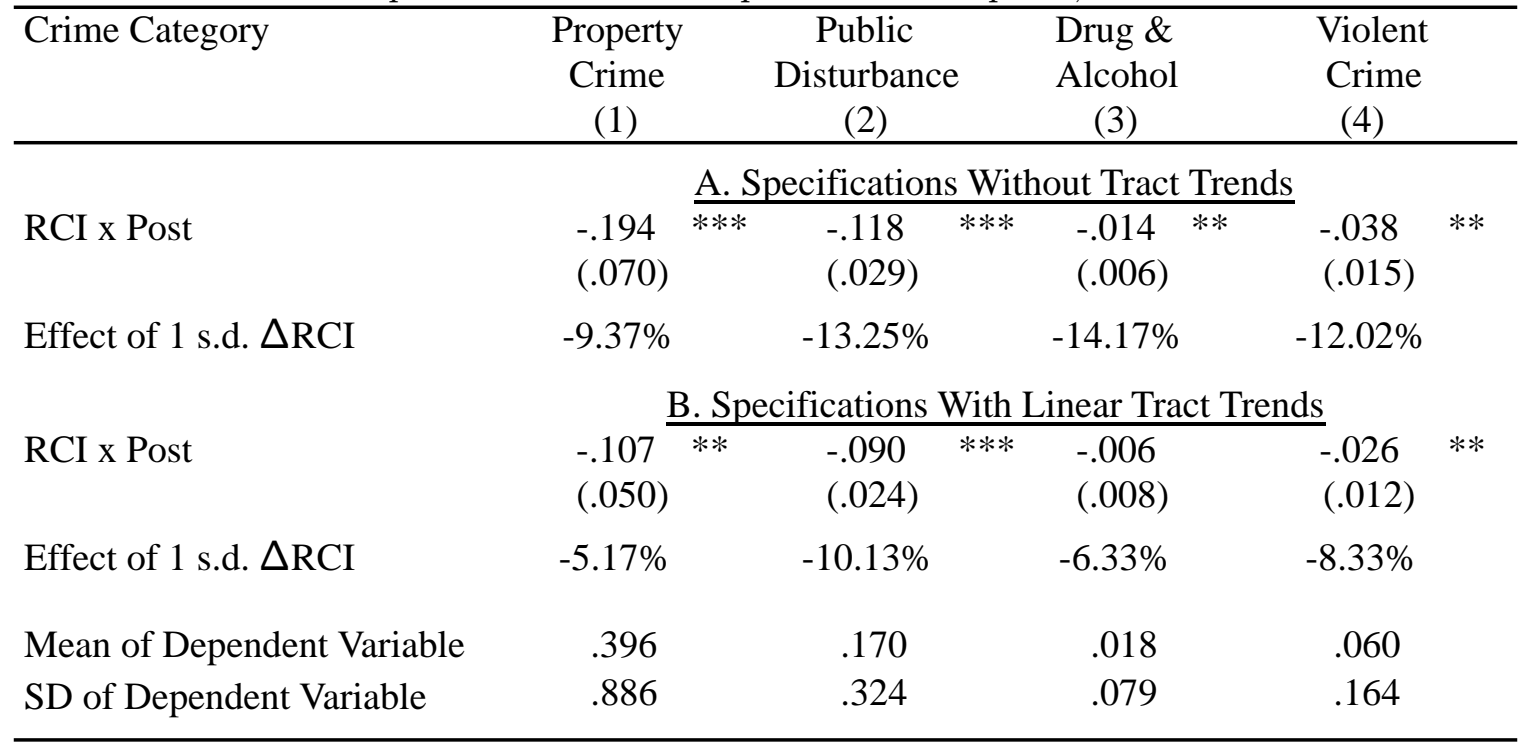

Notes: $\mathrm{N}=11,424, \lambda=12$. All specifications include year fixed effects and fixed effects for 816 adjusted blocks. Standard errors in parentheses clustered at the block level. The mean of RCI term is 0.392, and the standard deviation of RCI term is 0.218 .

$* * * \mathrm{p}<0.01, * * \mathrm{p}<0.05, * \mathrm{p}<0.1$ 
Table 5: Effect of Rent Control Intensity: Alternative Functional Forms

\begin{tabular}{|c|c|c|c|c|c|c|c|c|c|c|}
\hline \multirow[t]{2}{*}{ Exponential Weight } & \multicolumn{4}{|c|}{$\lambda=3$} & \multicolumn{2}{|c|}{$\lambda=12$} & \multicolumn{4}{|c|}{$\lambda=\infty$} \\
\hline & $(1)$ & & $(2)$ & & (3) & $(4)$ & $(5)$ & & $(6)$ & \\
\hline Second RCI Tercile x Post & $\begin{array}{l}-.016 \\
(.028)\end{array}$ & & $\begin{array}{l}-.007 \\
(.028)\end{array}$ & $\underline{\text { A. } T}$ & 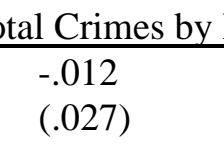 & 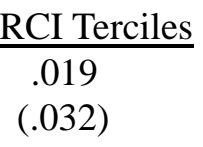 & $\begin{array}{l}-.055 \\
(.031)\end{array}$ & $*$ & $\begin{array}{l}-.047 \\
(.027)\end{array}$ & $*$ \\
\hline Third RCI Tercile $\mathrm{x}$ Post & $\begin{array}{l}-.171 \\
(.048)\end{array}$ & $* * *$ & $\begin{array}{l}-.141 \\
(.038)\end{array}$ & $* * *$ & $\begin{array}{l}-.149 \quad * * * \\
(.049)\end{array}$ & $\begin{array}{l}-.110 \quad * * * \\
(.040)\end{array}$ & $\begin{array}{l}-.167 \\
(.052)\end{array}$ & $* * *$ & $\begin{array}{l}-.135 \\
(.045)\end{array}$ & *** \\
\hline RCI x Post & $\begin{array}{l}-.379 \\
(.306)\end{array}$ & & $\begin{array}{l}-.241 \\
(.333)\end{array}$ & & $\frac{\text { B. FE Poisson }}{-.285 *}$ & $\frac{\text { Model }}{-.250}$ & $\begin{array}{l}-.147 \\
(.089)\end{array}$ & $*$ & $\begin{array}{l}-.123 \\
(.086)\end{array}$ & \\
\hline Linear Tract Trends & $\mathrm{NO}$ & & YES & & NO & YES & NO & 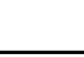 & YES & \\
\hline
\end{tabular}

$* * * \mathrm{p}<0.01, * * \mathrm{p}<0.05, * \mathrm{p}<0.1$ 
Table 6: Effect of Initial Crime Level on Crime

Dependent Variable: Total Crime per $1,000 \mathrm{~m}^{2}$

\begin{tabular}{lllll}
\hline & $(1)$ & $(2)$ & $(3)$ & $(4)$ \\
\hline RCI x Post & $-.339 * * *$ & & .040 & $-.215 *$ \\
& $(.102)$ & & $(.073)$ & $(.116)$ \\
Initial Crime x Post & & $-.277 * * *$ & $-.279 * * *$ & $-.141 * * *$ \\
& & $(.055)$ & $(.056)$ & $(.056)$ \\
RCI x Initial Crime x Post & & & & $-.784 * * *$ \\
& & & & $(.267)$ \\
R-squared & .852 & .865 & .865 & .866 \\
\hline N & & & & \\
\hline
\end{tabular}

Notes: $\mathrm{N}=10,608$. RCI is defined with $\lambda=12$. All specifications include year fixed effects and fixed effects for 816 adjusted Census blocks. Standard error is clustered at the adjusted block level. RCI, and Initial Crime variables are demeaned.

$* * * \mathrm{p}<0.01, * * \mathrm{p}<0.05, * \mathrm{p}<0.1$ 
Table 7: Effect of RCI and Initial Crime on Crime Categories Dependent Variable: Reported Crimes per $1,000 \mathrm{~m}^{2}$

\begin{tabular}{|c|c|c|c|c|c|c|c|c|}
\hline Crime Category & $\begin{array}{c}\text { Property } \\
\text { Crime } \\
\text { (1) }\end{array}$ & & $\begin{array}{c}\text { Public } \\
\text { Disturbanc } \\
\text { (2) }\end{array}$ & & $\begin{array}{c}\text { Drug \& } \\
\text { Alcohol } \\
\text { (3) }\end{array}$ & & $\begin{array}{l}\text { Violent } \\
\text { Crime } \\
(4)\end{array}$ & \\
\hline RCI x Post & $\begin{array}{l}-.123 \\
(.083)\end{array}$ & & $\begin{array}{l}-.093 \\
(.030)\end{array}$ & $* * *$ & $\begin{array}{l}-.023 \\
(.013)\end{array}$ & $*$ & $\begin{array}{l}-.019 \\
(.022)\end{array}$ & \\
\hline Initial Crime $\mathrm{x}$ Post & $\begin{array}{l}-.121 \\
(.067)\end{array}$ & & $\begin{array}{l}-.235 \\
(.063)\end{array}$ & $* * *$ & $\begin{array}{l}-.160 \\
(.119)\end{array}$ & & $\begin{array}{l}-.131 \\
(.107)\end{array}$ & \\
\hline RCI x Initial Crime x Post & $\begin{array}{l}-.892 \\
(.303)\end{array}$ & $* * *$ & $\begin{array}{l}-.698 \\
(.160)\end{array}$ & $* * *$ & $\begin{array}{r}-1.734 \\
(.843)\end{array}$ & $* *$ & $\begin{array}{l}-.557 \\
(.333)\end{array}$ & $*$ \\
\hline Effect of 1 s.d. $\Delta$ RCI & $-5.80 \%$ & & $-9.98 \%$ & & $-23.21 \%$ & & $-6.07 \%$ & \\
\hline Mean of Dependent Variable & .406 & & .179 & & .019 & & .060 & \\
\hline SD of Dependent Variable & .912 & & .338 & & .084 & & .150 & \\
\hline
\end{tabular}

Notes: $\mathrm{N}=10,608, \lambda=12$. All specifications include year fixed effects and fixed effects for 816 adjusted blocks. Standard errors in parentheses clustered at the block level. The mean of RCI term is 0.392 , and the standard deviation of RCI term is 0.218 .

$* * * \mathrm{p}<0.01, * * \mathrm{p}<0.05, * \mathrm{p}<0.1$ 


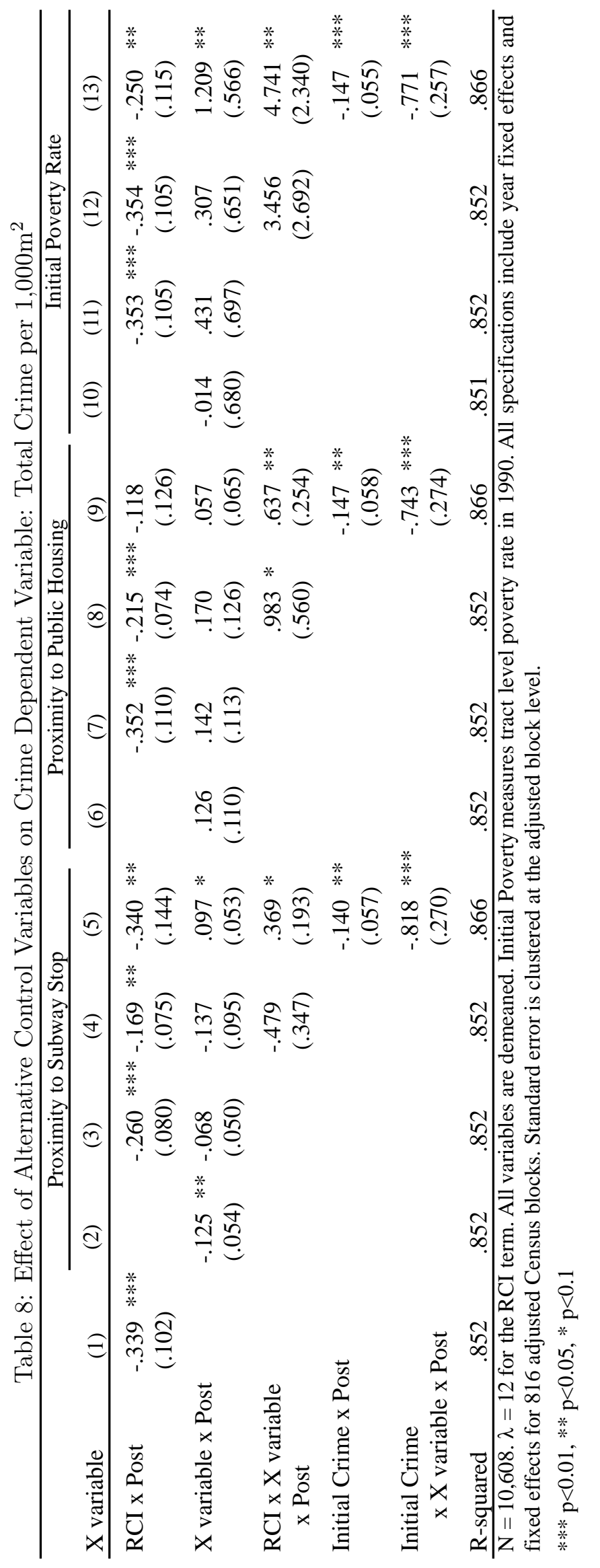




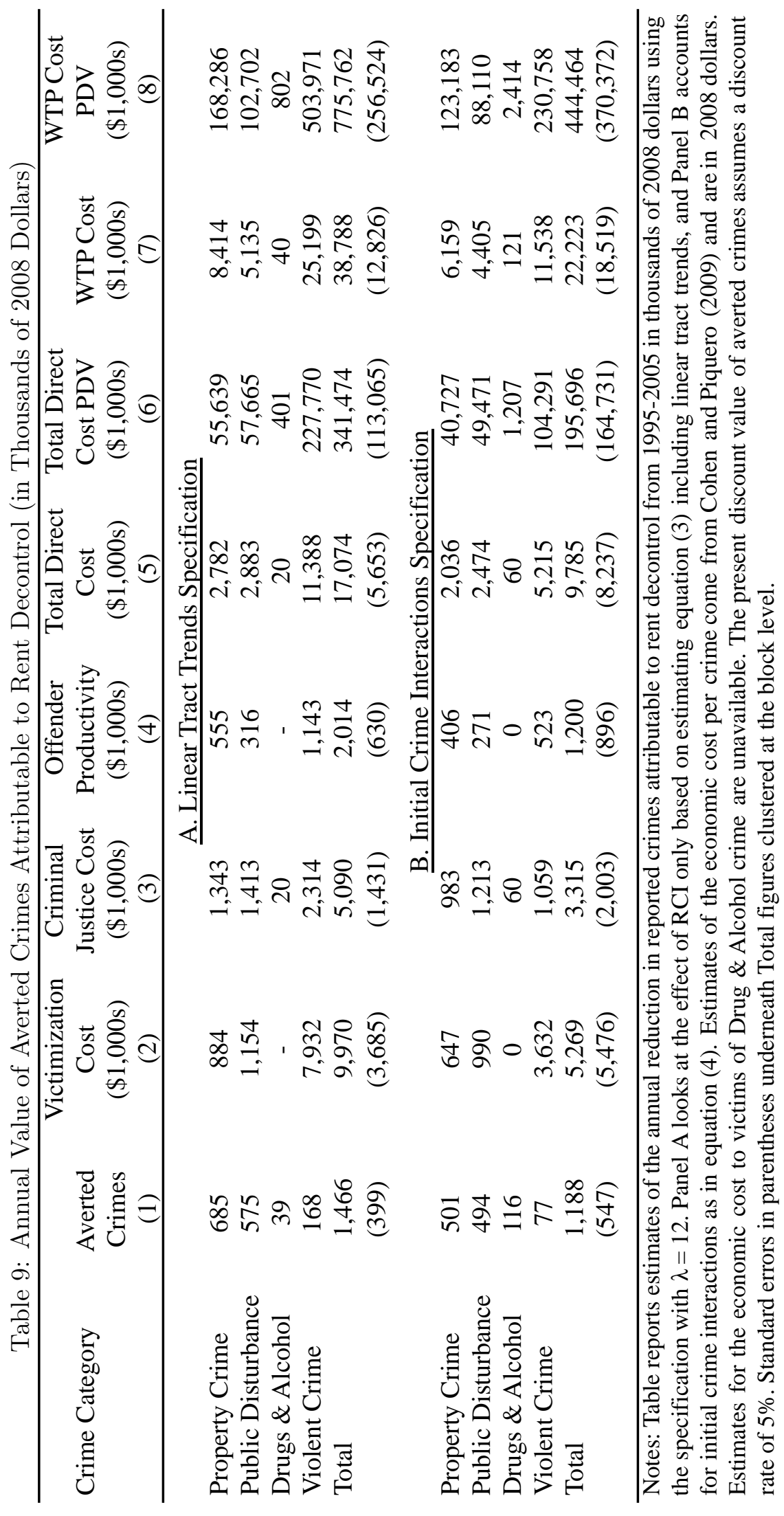


Table 10: Effect of RCI on Property and Crime Values

\begin{tabular}{|c|c|c|c|c|}
\hline & $(1)$ & $(2)$ & (3) & $(4)$ \\
\hline & \multicolumn{4}{|c|}{ A. Effects on Property Values and Total Cost of Crime } \\
\hline & \multicolumn{2}{|c|}{$\frac{\text { Total Property }}{\underline{\text { Value }}} \quad \frac{\text { Residential }}{\underline{\text { Property }}}$} & $\underline{\text { Total Direct }}$ & $\frac{\text { WTP to Avoid }}{\underline{\text { Crime }}}$ \\
\hline RCI x Post & $\begin{array}{l}522.841 \text { *** } \\
(184.036)\end{array}$ & $\begin{array}{c}437.103 \\
(179.796)\end{array}$ & $\begin{array}{l}-4.069 \text { *** } \\
(1.444)\end{array}$ & $\begin{array}{l}-8.970 * * * \\
(3.270)\end{array}$ \\
\hline $\begin{array}{l}\text { Crime Share of } \\
\text { Appreciation }\end{array}$ & $\mathrm{n} / \mathrm{a}$ & $\mathrm{n} / \mathrm{a}$ & $16 \%$ & $34 \%$ \\
\hline \multirow[t]{3}{*}{ R-squared } & .881 & .881 & .871 & .881 \\
\hline & \multicolumn{4}{|c|}{ B. Cost of Crime Robustness to Violent Crime Treatment } \\
\hline & \multicolumn{2}{|c|}{$\underline{\frac{\text { Total Cost of }}{\text { Nonviolent Crimes }}}$} & \multicolumn{2}{|c|}{$\frac{\text { Total Cost of }}{\text { Violent Crimes }}$} \\
\hline RCI x Post & $\begin{array}{rl}-1.372 & * * * \\
(.455) & \end{array}$ & $\begin{array}{r}-1.648 \\
(.463)\end{array}$ & $\begin{array}{l}-2.697 \quad * * \\
(1.259)\end{array}$ & $\begin{array}{c}2.645 \\
(3.886)\end{array}$ \\
\hline $\begin{array}{l}\text { Crime Share of } \\
\text { Appreciation }\end{array}$ & $5 \%$ & $6 \%$ & $10 \%$ & $-10 \%$ \\
\hline Categorization Method & d Coarse & Fine & Coarse & Fine \\
\hline R-squared & .884 & .857 & .797 & .567 \\
\hline
\end{tabular}

$\mathrm{N}=1,632$. Table reports regressions of block by year property values and total cost of crime on Rent Control Intensity interacted with an indicator for 2002, year fixed effects (1994 and 2002) and 816 adjusted Census block fixed effects. Crime Share of Appreciation row capitalizes the annual cost of crime estimates into stocks assuming a 5\% discount rate and calculates the share of the effect of the end of rent control on property values (panel A column 1) attributable to reductions in crime. Panel $B$ investigates the total cost of nonviolent crimes (columns 1 and 2) and violent crimes (columns 3 and 4) in the total cost of crime measures using coarse (columns 1 and 3) and fine (columns 2 and 4) methods of categorizing crimes. Coarse categories and costs (also used in Panel A columns 3 and 4) are given in Appendix Table A2. Fine categories and costs are given in Table 5 of Cohen and Piquero (2009). Standard errors in parentheses clustered at the block level.

$* * * \mathrm{p}<0.01, * * \mathrm{p}<0.05, * \mathrm{p}<0.1$ 


\section{Data Appendix}

Appendix Figure A3 shows that Cambridge had between 500-1,000 violent crimes annually and 3,000-6,000 property crimes annually from 1992-2005; total crimes in both categories declined steadily and mostly leveled off by 1999. Each year, the FBI publishes Uniform Crime Reports that use common definitions of violent and property crimes to disseminate local jurisdiction-provided estimates of total annual crimes. Importantly, aggregate annual crime counts derived from our microdata match up well with the city-wide counts CPD provided to the FBI contemporaneously. In the later years - starting with the commencement of digital crime-logging in 1997-the difference between totals reported by CPD to the FBI, our raw data, and our geocoded data are negligible. The ungeocoded data in the early years also track the aggregates trends well. The data quality in the early years is such that we lose many more observations from the geocoding process before the 1997 adoption of electronic record keeping than after ${ }^{18}$

Appendix Figure A1 shows the relative importance of each of our crime categories. Total crime in Cambridge (blue line) has mostly ranged between 6,000-8,000 annual crimes, the majority of which are property crimes and public disturbances (around 2,000 crimes per year). Violent crimes, while much more harmful to victims and neighborhoods, are relatively rare, and reported drug and alcohol crimes are the least common of the five categories.

\footnotetext{
${ }^{18}$ Note that to form our sample of crime incidents, we ignore a large number of crimes without an obvious geographical component including motor-vehicle violations, hit and runs, violations of warrants or summonses, and restraining-order violations.
} 
Figure A1: Trends in Crime by Category, 1992-2005

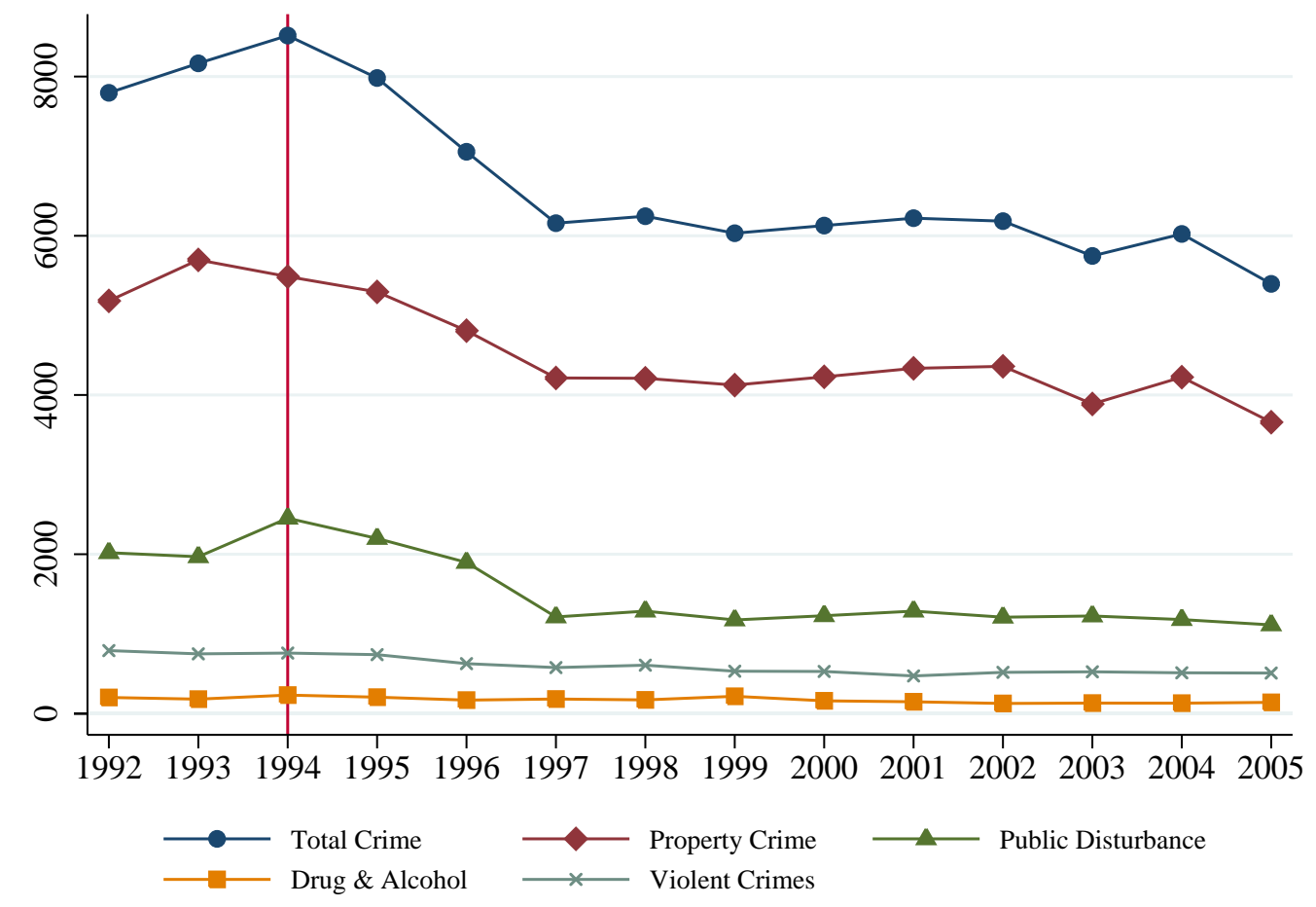

Notes: Graph plots counts of crimes in Cambridge by category for each year in our data before geocoding. The vertical line at 1994 indicates the last year of rent control regulations. 
Figure A2: Sum of Squared Errors by $\lambda$

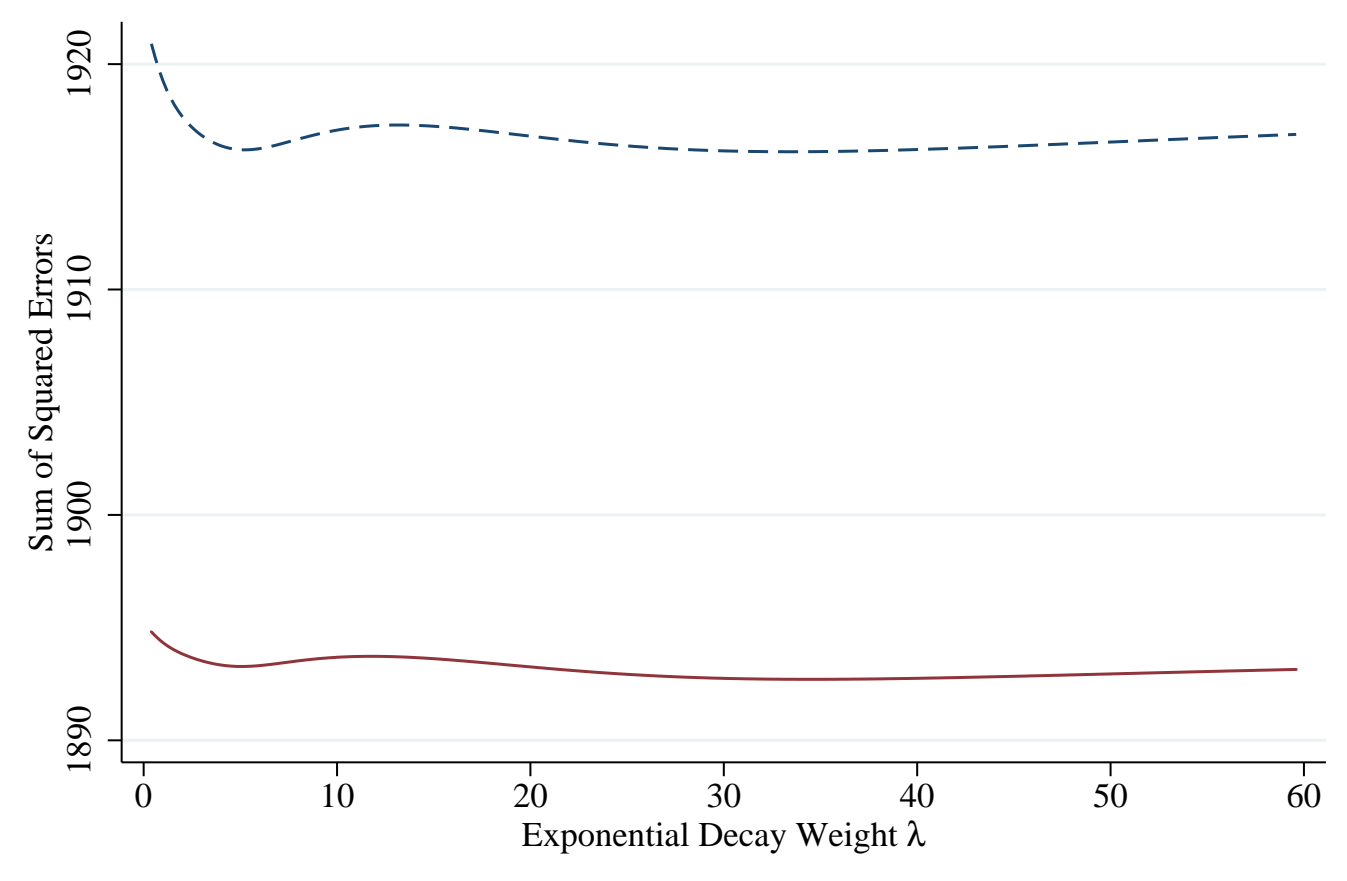

---- Without Tract Trends $\quad$ With Tract Trends

Notes: Figure plots the minimized sum of squared errors (SSE) from estimating equation (3) for a given value $\lambda$ of the exponential decay weighting parameter in the definition of Rent Control Intensity in equation (2). The solid red and dashed blue lines plot minimum SSE for specifications without and with linear tract trends, respectively. 
Figure A3: Aggregate Crime Counts by Data Source, 1992-2005
A. Violent Crimes
B. Property Crimes
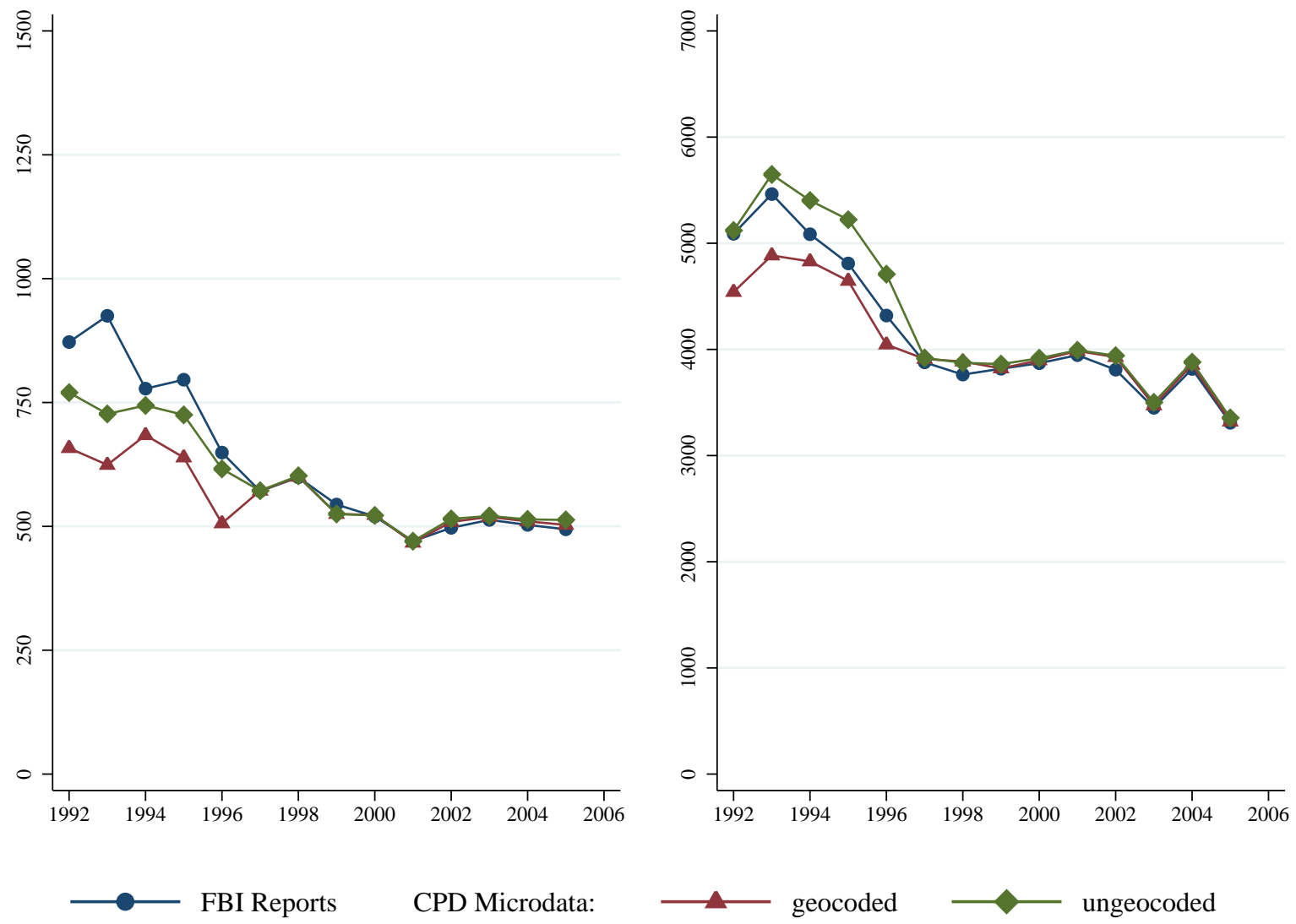

Notes: Panels A and B plot the total number of violent and property crimes, respectively, in Cambridge for each year of our data. Lines with blue circles are statistics from the FBI Uniform Crime Reports reported contemporaneously by the Cambridge Police Department. Lines with green diamonds are the total counts from our microdata prior to geocoding. Red-triangle lines report annual crime counts for only those crimes we were able to successfully geolocate. 
Table A1: Spatially Correlated Standard Errors Dependent Variable: Total Crime per 1000m²

\begin{tabular}{lc}
\hline Exponential Weight & $(1)$ \\
\hline RCI x Post & $-0.315 * * *$ \\
Clustered SE & $(0.095)$ \\
Spatial SE (0.5 mile ) & $(0.067) * * *$ \\
Spatial SE (1 mile ) & $(0.065) * * *$ \\
Spatial SE (3 miles ) & $(0.043) * * *$ \\
\hline
\end{tabular}

Linear Tract Trends

NO

$\mathrm{N}=11,424$. All specifications include year fixed effects and fixed effects for 816 adjusted Census blocks.

$* * * \mathrm{p}<0.01, * * \mathrm{p}<0.05, * \mathrm{p}<0.1$ 
Table A2: Weighted Cost per Crime

\begin{tabular}{lccccc}
\hline & Victimization & Criminal & Offender & Productivity \\
Crime Category & Cost & Justice Cost & Cost & Cost & Wirect \\
& $(1)$ & $(2)$ & $(3)$ & $(4)$ & WTP Cost \\
\hline Property Crime & $\$ 1,291$ & $\$ 1,962$ & $\$ 811$ & $\$ 4,064$ & $\$ 12,291$ \\
Public Disturbance & $\$ 2,006$ & $\$ 2,457$ & $\$ 549$ & $\$ 5,012$ & $\$ 8,926$ \\
Drugs \& Alcohol & - & $\$ 520$ & - & $\$ 520$ & $\$ 1,040$ \\
Violent Crime & $\$ 47,218$ & $\$ 13,772$ & $\$ 6,804$ & $\$ 67,794$ & $\$ 150,003$ \\
Weighted Average & $\$ 5,400$ & $\$ 3,061$ & $\$ 1,250$ & $\$ 9,711$ & $\$ 23,170$ \\
\hline
\end{tabular}

Notes: Table reports the weighted costs per crime in 2008 dollars. Cost estimates for the most common offenses from Cohen and Piquero (2009) are weighted their relative within-category frequency in Cambridge. 